Canadian

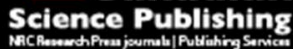

Canadian Geotechnical Journal Revue canadienne de géotechnique

\title{
Influence of End Effect on Rock Strength in True Triaxial Compression Test
}

\begin{tabular}{|r|l|}
\hline Journal: & Canadian Geotechnical Journal \\
\hline Manuscript ID & cgj-2016-0393.R2 \\
\hline Manuscript Type: & Article \\
\hline Date Submitted by the Author: & 13-Jan-2017 \\
\hline Complete List of Authors: & $\begin{array}{l}\text { Xu, Yuhang; Laurentian University Faculty of Science and Engineering } \\
\text { Cai, Ming; Laurentian University Faculty of Social Sciences and Humanities } \\
\text { Zhang, Xiwei; Northeastern University } \\
\text { Feng, Xia-Ting; Chinese Academy of Sciences }\end{array}$ \\
\hline Keyword: & $\begin{array}{l}\text { True triaxial compression test, intermediate principal stress, rock strength, } \\
\text { end effect, numerical modeling }\end{array}$ \\
\hline &
\end{tabular}




\section{Abstract}

\title{
Influence of End Effect on Rock Strength in True
}

\section{Triaxial Compression Test}

\author{
Y.H. Xu ${ }^{1,2}$, M. Cai ${ }^{1,2,3^{*}}$, X.W. Zhang ${ }^{4}$, X.T. Feng ${ }^{3,4}$
}

1. Bharti School of Engineering, Laurentian University, Sudbury, Ont., Canada P3E 2C6

2. MIRARCO, Laurentian University, Sudbury, Ont., Canada P3E 2C6

3. State Key Laboratory of Geomechanics and Geotechnical Engineering, Institute of Rock and Soil Mechanics, Chinese Academy of Sciences, Wuhan, 430071, China

4. Key Laboratory of Ministry of Education for Safe Mining of Deep Metal Mines, Northeastern University, Shenyang 110004, China

(*Corresponding author: Ming Cai (mcai@laurentian.ca))

The influence of the end effect on rock strength in true triaxial compression test was studied using a numerical approach. The influence of $\sigma_{2}$ on rock strength was isolated by using the 2D Mohr-Coulomb failure criterion that depends only on $\sigma_{1}$ and $\sigma_{3}$. Thus, any enhancement to the rock strength with the increase of $\sigma_{2}$ can be attributed to the end effect. It was shown that the end effect can result in an apparent $\sigma_{2}$ effect, as long as the coefficient of friction $(\mu)$ at rock specimen-steel platen contacts is not zero and the specimen in the $\sigma_{2}$ loading direction is squat. When the strengthening due to the increase of $\sigma_{2}$ predicted by a theoretical failure criterion was 
21 added to the strengthening due to the end effect, the results were in good agreement with the

22 observed $\sigma_{2}$ effect from some previous laboratory tests, indicating that the observed $\sigma_{2}$ effect in

23 true triaxial compression test could be partially influenced by the end effect, particularly when $\sigma_{3}$

24 was low. It is suggested to decrease the end effect to a level where the apparent $\sigma_{2}$ effect is very

25 small so that the obtained test results are more meaningful to characterize the actual $\sigma_{2}$ effect.

26 Keywords: True triaxial compression test; intermediate principal stress; rock strength; end effect;

27 3D empirical failure criterion; numerical modeling

28 


\section{Introduction}

30 Accurate estimation of rock strength is one the most important tasks in rock engineering design.

Different approaches including laboratory, theoretical, empirical, and numerical approaches have been developed and used to investigate rock strength (Hudson et al., 1972; Read and Hegemier, 1984; Dai et al., 2010; Xu et al., 2016) and many failure criteria have been developed to model rock strength. Among them, the 2D Mohr-Coulomb (M-C) and Hoek-Brown (H-B) failure criteria, which are based on conventional triaxial $\left(\sigma_{1}>\sigma_{2}=\sigma_{3}\right)$ compression test results and do not take the intermediate principal stress $\left(\sigma_{2}\right)$ into account, have been widely used to estimate rock strength. Although a rock mass is generally under a true triaxial stress state $\left(\sigma_{1}>\sigma_{2}>\sigma_{3}\right)$ in situ, it is commonly accepted that "a simplification to ignore the influence of intermediate principal stress on rock material strength is justifiable" (Brown, 2008). Moreover, there is no significant deviation of predicted rock strengths between the results using these 2D failure criteria and field measurements, suggesting that these simple failure criteria are reliable (Hoek et al., 2002; Eberhardt, 2012; Labuz and Zang, 2012). In addition, the well-known Griffith theory, developed from a theoretical approach, also ignores the effect of $\sigma_{2}$ in its original form.

47 observed that $\sigma_{2}$ had a large effect on rock strength. Similar results were later reported by other investigators (Wiebols and Cook, 1968; Michelis, 1987; He et al., 2010; Li et al., 2015). In particular, Haimson and Chang (2000) developed a new true triaxial compression test apparatus and observed that rock strength increased significantly with the increase of $\sigma_{2}$. The observed $\sigma_{2}$

51 effect is normally characterized by an increase of rock strength with the increase of $\sigma_{2}$, followed 
52 by reaching a strength plateau and a strength drop soon after with the further increase of $\sigma_{2}$ (Fig.

53 1). It should be noted that while the $\sigma_{2}$ effect has been widely reported from most laboratory test

54 results, the observed strengthening effect of $\sigma_{2}$ on some rocks is not significant (Takahashi and

55 Koide, 1989; Chang and Haimson, 2005). Nevertheless, these laboratory observations provoked

56 the attention of considering $\sigma_{2}$ in 3D empirical failure criteria (Mogi, 1967, 1971; Haimson and

57 Chang, 2000; Al-Ajmi and Zimmerman, 2005; You, 2009).

In this study, a method to quantify the observed $\sigma_{2}$ effect is proposed and is schematically

59 shown in Fig. 1. Blue point $\left(0, \sigma_{\mathrm{c}}\right)$ represents the uniaxial compressive strength (UCS, or $\left.\sigma_{\mathrm{c}}\right)$;

60 blue points $\left(\sigma_{2}, \sigma_{1}\right)$ represent conventional triaxial stress states at different $\sigma_{3}$; and red points $\left(\sigma_{2}{ }^{*}\right.$,

$\left.61 \sigma_{1}{ }^{*}\right)$ represent the stress state at the strength plateaus at different $\sigma_{3}$. The slope between point $\left(\sigma_{2}\right.$,

$\left.62 \sigma_{1}\right)$ at the origin of the $\sigma_{1}-\sigma_{2}$ curve and point $\left(\sigma_{2}{ }^{*}, \sigma_{1}{ }^{*}\right)$ at the summit of the $\sigma_{1}-\sigma_{2}$ curve gives

63 the maximum percentage increase of rock strength caused by $\sigma_{2}$. In this way, the strengthening

64 effect of $\sigma_{2}$ on different rocks can be quantified.

Basing on the published data of true triaxial compression tests, some of the observed $\sigma_{2}$

66 effects are quantified and summarized in Table 1. Test results that do not show the strength

67 plateau in the $\sigma_{1}-\sigma_{2}$ curves are not included. It is seen that the $\sigma_{2}$ effect is not the same in

68 different rocks. Moreover, it seems that the observed $\sigma_{2}$ effect on rock strength is more

69 significant when the applied $\sigma_{3}$ is low, and it decreases with the increase of $\sigma_{3}$. For instance, an

70 unusually high percentage of strength increase of $114 \%$ for Westerly granite is observed at $\sigma_{3} / \sigma_{\mathrm{c}}$

$71=0$, and it drops to $49 \%$ at $\sigma_{3} / \sigma_{\mathrm{c}}=0.38$.

72 There are arguments on the adequacy of some of the test results that show significant

73 influence of $\sigma_{2}$ on rock strength. Colmenares and Zoback (2002) concluded that $\sigma_{2}$ hardly 
74 affected the strength of some rocks and in such cases the 2D M-C and H-B failure criteria fitted

75 the test data equally well, or even better, than more complicated 3D failure criteria. Cai (2008b)

76 clarified numerically that spalling and onion-skin formation in underground opening was mainly

77 attributed to the existence of $\sigma_{2}$, and $\sigma_{2}$ had a limited influence on rock strength when $\sigma_{3}$ was

78 low. This statement tends to agree with field observation at the URL Mine-by tunnel (Cai and

79 Kaiser, 2014) and theoretical prediction from Wiebols and Cook (1968). Accordingly, Cai

80 (2008b) pointed out that a large percentage increase of rock strength due to $\sigma_{2}$, as observed from

81 some laboratory tests, was mainly attributed to the end effect.

End effect exists ubiquitously in rock laboratory tests (Fig. 2), and it is initiated under

83 compression due to the elastic mismatch between the rock specimen and the metal platens and

84 the friction between them (Hoskins and Horino, 1968; Choi et al., 1996). It is practically

85 impossible to exclude the end effect completely from rock property testing, even if anti-friction

86 measures are employed (Brady, 1971). For instance, the relation between end effect and

87 slenderness effect is a well-studied subject from the 1960s to the 1990s (Babcock, 1969; Brady,

88 1971; Kotsovos, 1983; Tang et al., 2000). Laboratory studies on the slenderness effect show that

89 the use of lubricants to minimize the end effect is sometimes not effective (Meikle and Holland,

90 1965; Pellegrino et al., 1997; Liang et al., 2015).

End effect plays different roles in affecting the rock strength in different laboratory tests.

92 In uniaxial compression test, the end effect has a large influence on the rock strength when the

93 specimen is squat (Fig. 2) (Bieniawski and Bernede, 1979). In conventional triaxial compression

94 test, Mogi (2007) concluded that the end effect in triaxial compression test can be greatly

95 reduced with the increase of confinement. There is still a lack of systematic investigation on how

96 the end effect affects rock strength in true triaxial compression tests. Compared with the 
97 conventional triaxial compression test, which employs hydraulic pressure to apply lateral

98 confinement and hence has very little or no friction-induced constraint at the lateral surfaces of

99 the specimen, friction exists at the lateral rock specimen-metal platen contacts in true triaxial 100 compression test because metal platens are normally used to apply either $\sigma_{2}$ or both $\sigma_{2}$ and $\sigma_{3}$.

101 Thus, the end effect's influences on rock strength between these two types of triaxial 102 compression tests are different. More importantly, the end effect usually becomes more 103 significant when the specimen is squatter $(\mathrm{H} / \mathrm{W}<2)$. Fig. 3 illustrates that the ratio of the length 104 on the contact where $\sigma_{2}$ is applied $\left(l_{1}\right)$ to the length on the contact where $\sigma_{3}$ is applied $\left(l_{2}\right)$ is 1 in 105 most true triaxial compression tests. This is another reason that the end effect in true triaxial 106 compression test cannot be completely omitted due to the shape of the specimens. Accurate estimation of rock strength in a true triaxial stress state is driven by increased 108 tunneling activities at depth. It is thus necessary to study the influence of end effect on rock 109 strength in true triaxial compression test. In this study, we propose that the end effect exists in 110 true triaxial compression test and it can influence true triaxial compression test results and 111 thereby the interpretation of the actual $\sigma_{2}$ effect. It is hypothesized that the confined zones, 112 resulted by the end constraint near the rock specimen-steel platen contacts where $\sigma_{2}$ is applied, 113 can increase the actual $\sigma_{3}$ and hence the rock strength. Furthermore, enlightened by some 114 indirect evidences, it is reckoned that different deformation behaviors of rocks can result in 115 different levels of end constraint near the contacts where $\sigma_{2}$ is applied, thus the observed $\sigma_{2}$ 116 effect can be different. Additionally, in true triaxial compression tests, the strengthening effect of 117 end constraint on rock strength may be more significant at low confinement and so is the 118 observed $\sigma_{2}$ effect. To verify our hypothesis, previous laboratory test results are used for model 
119 calibration, and a numerical experiment using the ABAQUS/Explicit Finite Element Method 120 (FEM) tool is carried out.

121 Numerical simulation of true triaxial compression test

122 Selection of published true triaxial compression test results

123 True triaxial compression test has become popular in recent years and there are a number of true 124 triaxial compression test apparatuses for soil, concrete and rock testing (Shi et al., 2012). It is 125 necessary to select test results with precaution for this numerical study. Firstly, the reliability of a 126 true triaxial compression test apparatus should be well recognized and the tests should be 127 conducted with a high level of repeatability under carefully controlled test conditions. Secondly, 128 test results with various rocks should be considered to ensure the validity of this numerical 129 experiment.

Basing on above considerations, we have chosen two types of true triaxial compression 131 test apparatuses and their corresponding test results. The first one is the Mogi-type machine,

132 which had been used to test seven types of rocks. We choose the test results of Solnhofen 133 limestone (Mogi, 2007), which shows clearly the influence of $\sigma_{2}$ on rock strength. We also 134 choose the test data of Takahashi and Koide (1989), who designed a true triaxial compression 135 test apparatus (a new Mogi-type machine) slightly different from Mogi's design to accommodate 136 larger specimens. The second type of apparatus was developed by Chang and Haimson (2000), 137 and we call it the Haimson-type machine. The major difference between these two types of 138 apparatuses is that the pistons of the Mogi-type machine that apply two perpendicular principal 139 stresses $\sigma_{1}$ and $\sigma_{2}$ are positioned in the vertical direction, while a biaxial apparatus is positioned 140 horizontally in the Haimson-type machine to apply $\sigma_{1}$ and $\sigma_{2}$. The test results of KTB 
141 amphibolite and Westerly granite by Chang and Haimson (2000), which are well known in the

142 field of true triaxial compression testing, are selected. Thus, representative test data of igneous

143 (granite), sedimentary (limestone, shale), and metamorphic (amphibolite) rocks are all included

144 in this study.

\section{Mohr-Coulomb failure criterion and modeling strategy}

146 The research focus is the influence of end effect on true triaxial compression test results. Because

147 the end effect inevitably exists in a true triaxial compression test, 3D empirical failure criteria

148 (Mogi, 1967; Al-Ajmi and Zimmerman, 2005) developed from true triaxial compression test

149 results might also contain rock strength strengthening due to the end effect. Therefore, a rock

150 model that excludes the influence of $\sigma_{2}$ effect on rock strength is preferable to study the

151 contribution of end effect to the observed $\sigma_{2}$ effect. As a result, the M-C failure criterion, which

152 does not consider $\sigma_{2}$, is used to define the rock strength while the actual contact condition of

153 rock specimen in a true triaxial compression test is modeled explicitly.

The 2D M-C failure criterion is one of the most commonly used failure criteria in rock engineering. As a failure criterion with mathematical simplicity, the physical meaning of the material parameters is clear. The rock strength of the $\mathrm{M}-\mathrm{C}$ failure criterion is defined by the

157 cohesive strength component and the frictional strength component (Martin, 1997;

158 Hajiabdolmajid et al., 2002; Mogi, 2007). Despite one of its shortcomings, i.e., the linear nature

159 of this failure criterion which may make it difficult to predict rock strength accurately when the 160 applied confinement is high (Hoek and Brown, 1997; Jaeger et al., 2007), the strength parameters 161 of the M-C failure criterion can be readily obtained or calibrated by performing simple rock 162 property testing. More importantly, unlike other materials, rocks exhibit a confinement163 dependent mechanical behavior, and rock failure under a moderate confinement is typically 
164 characterized by an inclined shear failure plane relative to the $\sigma_{1}$ loading direction (Hudson and 165 Harrison, 2000). The M-C failure criterion depicts the characteristic of rock strength and failure 166 type under confinement conditions satisfactorily. The shortcoming of the M-C failure criterion 167 for representing nonlinear failure envelopes of rocks in the $\sigma_{1}-\sigma_{3}$ space can be overcome by 168 restricting confinement within a limited range of interest (Pariseau, 2007; Mogi, 2007; Labuz 169 and Zang, 2012; Brady and Brown, 2013).

The modeling strategy of using a simple failure criterion can isolate the end effect in the

171 observed $\sigma_{2}$ effect. As it is hypothesized in this study, the end effect in a true triaxial

172 compression test can result in confined zones similar to that in an uniaxial compression test and

173 enhance the actual $\sigma_{3}$ of the rock and hence its strength. By increasing $\sigma_{2}$ in a true triaxial 174 compression test, if it is verified that a material whose strength is only $\sigma_{3}$-dependent experiences 175 a strengthening due to the end effect, then a both $\sigma_{3}$ and $\sigma_{2}$ dependent material, which is more 176 likely being the real material property of rocks, should be able to experience at least the same or 177 even greater strengthening with the same strengthening effect due to end constraint. This is 178 because that for rocks which are inherently confinement-dependent, the confinement they are 179 subjected to might not be exclusively caused by $\sigma_{3}$ loading. Instead, the confinement might be 180 influenced by $\sigma_{2}$ loading, leading to a combined influence of both $\sigma_{3}$ and $\sigma_{2}$ on rock strength. As 181 a result, the M-C failure criterion is considered suitable for the proposed investigation.

\section{Friction at rock specimen-steel platen contacts}

183 The coefficient of friction $(\mu)$ at rock specimen-steel platen contacts is an important parameter 184 that determines the end effect in rock laboratory tests (Gaffney, 1976). In this study, a set of tilt 185 tests was performed to determine a reasonable range of $\mu$ values for rock specimen-steel platen 
186 contacts. For a polished, smooth and dry rock specimen-steel platen contact without any 187 lubricants, the average tilting angle is about $15^{\circ}$, which gives a static $\mu$ of 0.27 .

In true triaxial compression tests, friction-reducing materials are routinely employed to 189 reduce the end constraints. Mogi (2007) employed Teflon sheets and thin copper shims as 190 lubricants. Takahashi and Koide (1989) used thin copper sheets and Teflon sheets with silicon 191 grease. Haimson and Chang (2000) inserted thin copper shims and stearic lubricant at the rock 192 specimen-steel platen contacts.

According to the aggregate state of the material zones involved, friction states can be classified as: solid friction, boundary friction, mixed friction, and fluid friction (Grote and Antonsson, 2009). Solid friction acts at direct contacts where material zones exhibit solid 196 properties; boundary friction refers to the boundary layers on the contacts, each consists of a molecular film coming from a lubricant; fluid friction occurs when lubricating film is created between the friction body surfaces to reduce wear; mixed friction is a mixed form of boundary and fluid frictions. Apparently, the friction state at a lubricated specimen-platen contact is neither a solid friction nor a fluid friction state. According to the Handbook of Mechanical Engineering (Grote and Antonsson, 2009), the $\mu$ value ranges for boundary and mixed frictions are $0.1-0.2$ and $0.01-0.1$, respectively.

For lubricated rock specimen-steel platen contacts, it is reported that the $\mu$ values can be 204 as low as 0.024 (He et al., 2014) and as high as 0.1 (Rashed and Peng, 2015), or even 0.39 in 205 some cases (Hawkes and Mellor, 1970). A $\mu$ value of 0.05 is reported in Labuz and Bridell (1993) 206 and a $\mu$ range of $0.04 \pm 0.003$ is given in the Handbook on Mechanical Properties of Rocks by 207 Vutukuri et al. (1974). Accordingly, friction at lubricated specimen-platen contacts can be in a 
208 mixed friction state. Hence, $\mu=0.05$ to 0.1 may seem to be an appropriate range to represent 209 friction at lubricated rock specimen-steel platen contacts.

It must be pointed out that the loading conditions in sliding tests (or direct shear test) 211 designed specifically to measure the coefficient of friction and that in rock laboratory strength 212 tests are different. Different testing arrangements can result in different test results. For instance, 213 instead of employing sliding tests to investigate the $\mu$ values for lubricated rock specimen-steel 214 platen contacts, Hawkes and Mellor (1970) first applied a torque to a cylinder steel block, which 215 was atop a hallow sandstone specimen, and then gradually relaxed the axial load concentrically 216 applied to the rock-steel system to measure the $\mu$ values under different contact conditions. The 217 obtained $\mu$ values for the lubricated specimen-platen contacts were noticeably higher than that 218 obtained by the sliding tests.

It is stated in the Handbook of Mechanical Engineering that "friction does not represent a 220 constant property of a material but rather depends on variables, e.g., on the load and the elements 221 involved in the friction process with their properties and interactions." The applied normal stress 222 on the sliding plane in a sliding test is not high, usually equivalent or slightly higher than the 223 pressure caused by the weight of the sliding body. In laboratory rock strength tests, the applied 224 normal stress on lubricated contacts is normally much higher than that used in sliding tests. 225 Therefore, the $\mu$ values of the lubricated specimen-platen contacts under high normal stresses 226 could be different than that revealed from the sliding tests and the effectiveness of using 227 lubricants in mitigating the end effect needs further investigation. In this numerical experiment, acknowledging that all the considered true triaxial 229 compression tests had employed anti-friction measures, base values of $\mu$ in the range of 0.05 to $230 \quad 0.1$ at the rock specimen-steel platen contacts were used in the modeling. To isolate the actual 
231 end effect as well as the potential $\sigma_{2}$ effect due to the end effect from true triaxial compression

232 test results, a minimum $\mu$ value of 0 was used. Finally, to appreciate the fact that the actual $\mu$

233 value under high normal stresses for some rocks might be different from that obtained by sliding

234 tests, a maximum $\mu$ value of 0.2 was used.

\section{FEM models}

The ABAQUS/Explicit FEM tool is considered suitable for this numerical experiment. Firstly, the potential increase of rock strength due to the end effect is the research focus and a precise modeling the fracture process of rocks using Discrete Element Method (DEM) is not necessary. Rock failure criteria like the M-C failure criterion that can be used to predict rock strength is available in the tool. Secondly, the tool can simulate complex contact behaviors for the rock specimen-steel platen contacts at a low computation cost. In addition, the explicit algorithm in the tool is preferred to solve nonlinear material and contact problems.

3D simulation models of cylinder specimens in uniaxial and conventional triaxial compression tests, and a square prism specimen in true triaxial compression test, as well as their corresponding loading conditions are shown in Fig. 4a, b, and c, respectively. Arrows in these figures show the direction of the principal stresses. Thick orange arrows indicate that the principal stress is applied by steel platens and thin blue arrows indicate that the principal stress is applied by hydraulic pressure. In the modeling, the applied $\sigma_{3}$ and $\sigma_{2}$ are pressure controlled, which means that once the applied principal stress reaches an assigned magnitude, the pressure will be hold constant on the applied surface. The applied $\sigma_{1}$ is displacement controlled, which means that $\sigma_{1}$ is applied at a constant strain rate. 
253 the heights of the specimens are $100 \mathrm{~mm}$. This gives a height to width ratio (H/W, or H/D for 254 cylinder specimens) of 2 , which is the same as that used in the laboratory tests. The top and 255 bottom steel platens are $51 \mathrm{~mm}$ in width (or diameter) and $25 \mathrm{~mm}$ in height (Fig. 4a - c). To 256 honor the laboratory test conditions, steel platen loading instead of hydraulic pressure loading is 257 used to apply $\sigma_{2}$ in the true triaxial compression test simulations. Two lateral steel platens used 258 for applying $\sigma_{2}$ are $50 \mathrm{~mm}$ in width, $98 \mathrm{~mm}$ in height, and $25 \mathrm{~mm}$ in thickness (Fig. 4c). Steel 259 properties $(E=200 \mathrm{GPa}, v=0.3)$ are assigned to the platens.

The FEM models of a cylinder specimen in both uniaxial and triaxial loading tests $\left(\sigma_{2}=\right.$ $\left.\sigma_{3} \geq 0\right)$ and a square prism specimen in true triaxial compression test are presented in Fig. 5. The

262 total numbers of hexagonal elements in the two specimens are 8844 and 9537 , which is relatively 263 fine for the stress modeling. The slight difference in element numbers between the two 264 specimens has little influence on their peak strengths, and this is verified by examining the 265 modeling results of rock strengths. Moreover, the FEM geometrical models for different rock 266 types under different true triaxial stress states are all the same (Fig. 5b).

\section{Calibration of material parameters}

268 Rock properties need to be calibrated first to carry out the numerical experiment. The rocks 269 calibrated in this study are hard rocks with UCS over $100 \mathrm{MPa}$, some are over 200 and $300 \mathrm{MPa}$ 270 (Section "Selection of published true triaxial compression test results"). The stress-strain curves 271 of the hard rocks are relatively linear in the pre-peak deformation stage (Chang and Haimson, 272 2000; Haimson and Chang, 2000; Mogi, 2007), especially before reaching the crack damage 273 threshold at a stress level of approximately 0.7 to 0.8 times of the peak strength where hard rocks 
274 basically exhibit elastic behavior. Therefore, the pre-peak deformation behavior of the rocks in 275 compression is simplified as linear elastic, as suggested by Fang and Harrison (2001) and Hoek 276 (2007). Young's modulus and Poisson's ratio are important elastic parameters to characterize the 277 deformation behavior of rocks, and their values can be readily obtained from the laboratory test 278 results provided in the origin works. Table 2 presents the physical and deformation parameters of 279 the rocks considered in the study.

The M-C failure criterion is used to determine the peak strengths of the rocks. The M-C 281 strength parameters - cohesion $(c)$ and friction angle $(\phi)$ - can be calibrated based on the 282 relations between $\sigma_{1}$ and $\sigma_{3}$ obtained from conventional triaxial test results. The M-C failure 283 criterion is a linear failure criterion that depicts a linear relation between $\sigma_{1}$ and $\sigma_{3}$. However, the 284 relation between $\sigma_{1}$ and $\sigma_{3}$ shown in conventional triaxial tests is nonlinear when the rock 285 specimens are subjected to high confinements (Section "Mohr-Coulomb failure criterion and 286 modeling strategy"). Thus, if only one set of M-C strength parameters are used to characterize 287 the rock behavior, a mismatch between the numerical and experimental results may occur, 288 especially when the range of confinement being simulated is large (e.g., $\sigma_{3}$ of 0 to $150 \mathrm{MPa}$ for 289 KTB amphibolite). Therefore, to characterize the rock behaviors well under different applied $\sigma_{3}$ 290 in the true triaxial compression tests, specimens under each applied $\sigma_{3}$ was assigned with 291 different sets of M-C strength parameters, calibrated based on the conventional triaxial test 292 results in a range of confinements which are close to the applied range of $\sigma_{3}$. 
296 the $\sigma_{1}-\sigma_{3}$ space. Thus, the M-C strength parameters, the cohesion and the friction angle, at each 297 applied $\sigma_{3}$ can be calibrated accordingly.

298 The strain-softening behavior was used to model the post-peak deformation behavior of 299 rocks. The evolution process of cracking in the post-peak deformation stage leads to a significant 300 cohesion loss (Martin, 1997). The cohesion loss can be modeled by the M-C failure criterion by 301 degrading the rock's cohesive strength as a function of plastic strain. Our numerical experiment 302 and laboratory true triaxial compression test focus on the peak strength of rocks, not the post303 peak deformation behavior. The strain-softening model is for the post-peak deformation behavior 304 modeling and it has no impact on the peak strength of rocks (Kias and Ozbay, 2013; Hemami 305 and Fakhimi, 2014; $\mathrm{Xu}$ and Cai, 2015). In addition, there are no solid laboratory test results of 306 complete stress-strain curves of rocks in true triaxial compression test due to the limitation of 307 test machines. Therefore, the post-peak deformation behavior of the rocks is not discussed in this 308 study.

\section{Simulation results}

\section{Deformation behavior}

311 The deformation behavior of rocks obtained from numerical modeling fits the laboratory test 312 data well, as long as the pre-peak deformation behavior of the rocks obtained in laboratory 313 testing is relatively linear. For instance, Westerly granite is a fine-grained, uniform, nearly 314 isotropic rock (Lockner, 1998). As illustrated in Fig. 6, the slope of the rock's pre-peak stress315 strain curve is basically linear for $\sigma_{2}=\sigma_{3}=60 \mathrm{MPa}$. Using the same Young's modulus and 316 Poisson's ratio obtained from the laboratory test (Table 2), the modeling results of both the 317 deformation behavior and the peak strength agree well with the test results, indicating that the 
318

319

320

321

322

323

324

325

326

327

329

330

331

332

333

numerical model is suitable for rock behavior modeling in uniaxial or triaxial stress states $\left(\sigma_{2}=\right.$ $\left.\sigma_{3} \geq 0\right)$

\section{Rock strength}

Fig. 7 to Fig. 10 compare the modeling results with the laboratory test results for KTB amphibolite, Westerly granite, Solnhofen limestone, and Yuubari shale, respectively. As mentioned above in Section "Friction at rock specimen-steel platen contacts", the exact $\mu$ value at the rock specimen-steel platen contacts that apply $\sigma_{2}$ are unknown in the laboratory tests and four values $(\mu=0,0.05,0.1,0.2)$ have been used in the numerical simulation. The $\mu$ values beside the rock name indicate the coefficient of friction at the specimen-platen contacts in the modeling, for both $\sigma_{1}$ and $\sigma_{2}$ loadings.

The dash lines in Fig. 7 to Fig. 10 represent the modeling results of conventional triaxial compression tests. All modeling results fit the laboratory test results well. Hence, the modeling strategy of using the linear M-C failure criterion to predict the rock strength under given range of confinement $\left(\sigma_{2}=\sigma_{3} \geq 0\right)$ is demonstrated. The applicability of the M-C failure criterion for predicting rock strength illustrated in this numerical experiment agrees with the conclusions drawn by other researchers (Pariseau, 2007; Labuz and Zang, 2012; Brady and Brown, 2013).

The solid lines in Fig. 7 to Fig. 10 represent the modeling results of true triaxial compression tests. All modeling results show that under each applied $\sigma_{3}$, rock strength $\left(\sigma_{1}\right)$ increases with the increase of $\sigma_{2}$ if the $\mu$ value is greater than 0 . There is a measurable increase of rock strength for $\mu=0.05$, a noteworthy increase of rock strength for $\mu=0.1$, and a significant increase of rock strength for $\mu=0.2$. It seems that the simulation results of all types of rocks fit the laboratory results well for $\mu=0.2$, suggesting that the simulation captured one characteristic 
340 of the observed $\sigma_{2}$ effect mentioned above, i.e., the observed $\sigma_{2}$ effect decreases with the 341 increase of applied $\sigma_{3}$.

342 If there is no end effect, i.e., the $\mu$ value is 0 at the specimen-platen contacts, the 343 modeling results show that the specimen's strength is independent of $\sigma_{2}$. This is because that the 344 2D M-C failure criterion was used and the increase of the specimen's strength is irrelevant of $\sigma_{2}$.

345 Note that there is a very small difference in the rock strengths given by the cylinder $\left(\sigma_{2}=\sigma_{3}\right)$ and 346 square prism $\left(\sigma_{2}>\sigma_{3}\right)$ geometrical models. This is caused by the geometrical model difference, 347 which is negligible as long as their loading conditions are the same $(\mu=0)$. For $\mu>0$, the 348 strengthening of the specimen is exclusively attributed to the end effect caused by $\sigma_{2}$. As will be 349 discussed in Section "Discussions", there is a legitimate $\sigma_{2}$ effect on rock strength. However, due 350 to the way that loads were applied in laboratory true triaxial compression tests, the test results 351 inevitably contain the influence of the end effect and a method to isolate the end effect from the 352 test data is proposed in Section "Discussions".

\section{Failure modes}

Fig. 11 to Fig. 13 present typical failure modes by the numerical simulation and the laberatery tests-of KTB amphibolite, Westerly granite, and Solnhofen limestone, respectively. The red zones in numerical 2D and 3D views represent the zones in which large plastic strains occur,

357 which can be used to indicate strain localization. The viewing plane for all the three figures is the $358 \sigma_{1}-\sigma_{3}$ plane $\left(15^{\circ}\right.$ rotation of the $\sigma_{1}$ axis for the $3 \mathrm{D}$ view $)$.

359 The simulation captures the characteristics of the failure modes of the true triaxial 360 compression test results (Chang and Haimson, 2000; Haimson and Chang, 2000; Mogi, 2007). With regard to the failure planes occurring on the $\sigma_{1}-\sigma_{3}$ plane and striking in the $\sigma_{2}$ loading 
362 direction, it is understood that $\sigma_{2}$ will constrain the failure planes in a way that the rock is easier 363 to fail in a direction parallel to the $\sigma_{2}$ loading direction (Cai, 2008b). For the KTB amphibolite 364 and the Westerly granite specimens, the numerical simulation results show conjugate fault planes 365 but only one fault plane was observed in the laboratory test. This may be due to the reason that 366 material heterogeneity was not considered in the numerical modeling. An approach had been 367 adopted in the numerical work of Senent et al. (2013) by introducing a very small defect in the 368 homogenous specimen to break the symmetry of the shear bands and a single fault plane was 369 successfully captured.

\section{Discussions}

\section{Relation between the $\sigma_{2}$ effect and the increase of actual $\sigma_{3}$}

372 The increase of rock strength in the numerical modeling result is not directly related to the 373 increase of $\sigma_{2}$, because the actual $\sigma_{2}$ effect is deliberately excluded from the assigned material 374 model. It is seen that friction mobilized at the specimen-platen contacts increases $\sigma_{3}$ in the 375 specimen and as a result the specimen's strength is increased. Resultant displacements on planes 376 cutting through the mid-height of the Westerly granite specimen in Fig. 14 show different modes 377 of lateral expansion under three loading conditions. In the conventional triaxial compression test 378 (Fig. 14a), the lateral expansions are relatively uniform and normal to the surface where 379 confinement is applied $\left(\sigma_{2}=\sigma_{3}=60 \mathrm{MPa}\right)$. In the true triaxial compression test, the expansions 380 in the direction where $\sigma_{2}$ is applied are smaller than that where $\sigma_{3}$ is applied. This is because that 381 it is easier for a specimen to expand in a direction in which it has less resistance. For the 382 specimen under the same applied $\sigma_{3}(60 \mathrm{MPa})$, the lateral expansions in the direction where $\sigma_{3}$ is 
383 applied increase with the increase of $\sigma_{2}$, leading to a larger relative deformation and hence a 384 greater end constraint at the contacts where $\sigma_{2}$ is applied (Fig. 14b and c).

Fig. 15 presents the contours of $\sigma_{3}$ on the side, top, and two vertical surfaces revealed 386 from a quarter cut of the specimen at peak load. Specifically, red zones, which represent a range 387 of $\sigma_{3}$ that is very close to the applied $\sigma_{3}(60 \mathrm{MPa})$, can be focused to evaluate the disturbance of 388 the actual $\sigma_{3}$ distribution due to the end effect. For the specimen under conventional triaxial 389 loading (Fig. 15a), because hydraulic pressure loading and pressure control are employed to 390 apply confinement, $\sigma_{3}=60 \mathrm{MPa}$ is maintained around the lateral surface of the cylinder 391 specimen. Therefore, the red zone is uniformly distributed and consists of the largest percentage 392 of the specimen volume. In comparison, even though hydraulic pressure loading and pressure 393 control are employed to apply $\sigma_{3}$ in true triaxial loadings, $\sigma_{3}=60 \mathrm{MPa}$ is maintained only on the 394 contacts where $\sigma_{3}$ is applied. In fact, there are more non-uniform distributions of $\sigma_{3}$ observed on 395 the contacts where $\sigma_{2}$ is applied and inside the specimen (Fig. 15b and c). Moreover, the 396 transition of the contour zones in the true triaxial loadings indicates that the actual $\sigma_{3}$ is increased 397 with the increase of $\sigma_{2}$.

It is inferred that the end constraint is activated on the specimen-platen contacts where $\sigma_{2}$

399 is applied because of the relative deformations of the specimen and the platens. The end 400 constraint acts on the contacts and inside the specimen in a direction coinciding with the $\sigma_{3}$ 401 direction, the actual $\sigma_{3}$ is thus increased in the specimen, leading to an increase of the specimen's 402 strength. End constraint acting on the specimen-platen contacts can be increased as an increase 403 of either the contact roughness ( $\mu$ value) or the normal stress $\left(\sigma_{2}\right)$. As a result, the specimen's 404 strength is increased with the increase of $\sigma_{2}$, even though the assigned specimen strength is 
405 independent of $\sigma_{2}$. In this numerical experiment of true triaxial compression test, the influence of 406 end effect on the increase of rock strength is studied. It is found that as long as the end effect 407 exists (i.e., the $\mu$ value is greater than 0), rock strengthening due to the end effect exists as well. 408 In the laboratory test results, this strength increase due to the end effect was not excluded and it 409 constituted part of the observed $\sigma_{2}$ effect.

\section{Complementary evidences related to end effect in true triaxial compression}

411 tests

412 Some rocks show a strength increase due to $\sigma_{2}$ while others do not, and different end constraints

413 initiated by different deformation behaviors of rocks could be the culprit. Using the same true 414 triaxial compression test apparatus and testing method, Chang and Haimson (2005) found that 415 the Long Valley Caldera rocks did not exhibit any meaningful $\sigma_{2}$ effect. After examining the 416 deviatoric stress $\left(\sigma_{1}-\sigma_{3}\right)$-volumetric strain $(\Delta \mathrm{V} / \mathrm{V})$ curves and the scanning electron microscope 417 results, we notice that the strength independency on $\sigma_{2}$ of the Long Valley Caldera rocks is due 418 to the non-dilatant deformation behavior of the rocks.

419 Fig. 16 show the deviatoric stress-volumetric strain curves for KTB amphibolite and 420 Long Valley Caldera metapelite in true triaxial compression tests (Chang and Haimson, 2000; 421 Chang and Haimson, 2005). It is seen that even though these two metamorphic rocks were tested 422 by the same true triaxial compression test apparatus, their deformation behaviors are different. 423 The deviatoric stress-volumetric strain curve of the amphibolite is nonlinear, indicating that 424 dilation develops gradually when the deviatoric stress is above $700 \mathrm{MPa}$, while that of the 425 metapelite is almost linear to the peak stress, indicating that there is an absence of dilation before 426 peak load. The reversal point in the amphibolite's deviatoric stress-volumetric strain curve 
427 marks the onset of unstable crack growth (i.e. crack damage threshold) that usually corresponds

428 to a stress level of approximately 0.7 to 0.8 times of the rock strength (Zhao and Cai, 2010).

429 From this point, the plastic volumetric strain rate outnumbers the elastic volumetric strain rate, 430 leading to a substantial growth of microcracks and dilation. Hence, for an amphibolite specimen 431 that experiences dilatancy in compression, the plastic volumetric strain resulting from the 432 dilation contributes to a large lateral expansion of the specimen before the peak load is reached. 433 This large lateral deformation of the rock led to high constraint from the loading platens and thus 434 the strength increase due to $\sigma_{2}$ was large. Enlightened by our modeling results - the lateral expansion in the mid-height of 436 specimens shown in Fig. 14 and the disturbance of actual $\sigma_{3}$ distribution in specimens in Fig. 15 437 - it becomes clear that if there is little lateral expansion (e.g., those two Long Valley Caldera 438 rocks), there will be very small relative deformation at the rock specimen-steel platen contacts 439 and the end effect is thus small. modeling results suggest that the end effect due to $\sigma_{2}$ can result in a strength increase even if the 442 rock strength used in the numerical modeling is independent of $\sigma_{2}$. Shi et al. (2012) used 443 FLAC3D to simulate the loading boundary effects in true triaxial compression test and revealed 444 that the end effect can result in an apparent $\sigma_{2}$ effect. Gerstle et al. (1978) and Gerstle et al. 445 (1980) carried out true triaxial compression tests on concrete specimens made from the same 446 material composition and concluded that the $\sigma_{2}$ effect varied considerably due to the different

447 loading methods and anti-friction measures. Therefore, the point highlighted in our study, i.e., 448 the end effect can result in a different interpretation of the $\sigma_{2}$ effect on rock strength, is supported 449 by the experimental results of Gerstle et al. (1978) and Gerstle et al. (1980). Uniaxial 
450 compression tests using well-polished, high strength Beishan granite (Zhao et al., 2012; Zhao et

451 al., 2013) revealed that even anti-friction measures were employed, rock strength was noticeably

452 increased if the H/D ratio of the cylinder specimen was decreased from 2 to 1 . Therefore, it is

453 practically impossible to neglect the end effect in true triaxial compression test results because

454 the $\mathrm{H} / \mathrm{W}$ ratio in the $\sigma_{2}$ direction is normally less than 1 ( 0.5 in most tests).

\section{Contribution of end effect to observed $\sigma_{2}$ effect}

456 It is numerically proved that when testing a rock-like material whose strength is independent of $457 \sigma_{2}$, there is an apparent $\sigma_{2}$ effect caused exclusively by the end effect. The next step is to confirm 458 that the apparent $\sigma_{2}$ effect constitutes part of the observed $\sigma_{2}$ effect in previous laboratory test 459 results. Although the actual $\mu$ values in previous true triaxial compression tests are unknown, the $460 \mu$ values can never be 0 and a range of 0.05 to 0.1 seems to be appropriate for lubricated rock 461 specimen-steel platen contacts (Section "Friction at rock specimen-steel platen contacts"). 462 Accordingly, laboratory test results that show a significant $\sigma_{2}$ effect might contain an apparent $\sigma_{2}$ 463 effect resulted from the end effect in a way similar to that revealed in our modeling results. It is 464 worth noting that, as justified in Section "Mohr-Coulomb failure criterion and modeling 465 strategy", although a $\sigma_{3}$-only-dependent material property might not be precise enough to 466 characterize the actual rock strength property, it is sufficient to emphasize the contribution of the 467 end effect to the observed $\sigma_{2}$ effect. The increase of rock strength due to the end effect in true 468 triaxial compression test simulations based on a both- $\sigma_{3}$-and- $\sigma_{2}$-dependent material model 469 should not be less than that based on a $\sigma_{3}$-only-dependent material model. 
472 and compared with the observed $\sigma_{2}$ effect in previous laboratory test results. Approaches that can 473 consider the actual $\sigma_{2}$ effect while excluding the end effect include theoretical approach 474 (Wiebols and Cook, 1968) and numerical investigation using the DEM (Fjær and Ruistuen, 2002;

475 Cai, 2008a; Schöpfer et al., 2013). DEM modeling employs micromechanical properties to 476 capture the failure process of rocks and thereby avoids the discretion of selecting an empirical 477 failure criterion that only reflects the macro-mechanical behavior of rocks. However, the 478 micromechanical parameters used in DEM modeling are hypothetical and cannot be measured in 479 laboratory tests. These parameters can only be obtained by trials-and-errors in the calibration 480 process while they are changed systematically until a set of parameters yield a macro behavior 481 that best fit the actual one (Potyondy and Cundall, 2004).

482 In this study, we choose the theoretically-based effective strain energy criterion 483 developed by Wiebols and Cook (1968) instead of the DEM modeling approach to characterize 484 the actual $\sigma_{2}$ effect. The effective strain energy criterion (Wiebols and Cook, 1968) was derived 485 based on a hypothesis that the effective shear strain energy stores around Griffith cracks due to 486 the sliding of crack surfaces, and rock failure occurs when the total effective shear strain energy, 487 which depends on the coefficient of sliding friction $\left(\mu_{\mathrm{s}}\right)$ of the crack surfaces, reaches a critical 488 value. It predicts a strengthening of rock from increasing $\sigma_{2}$ followed by a strength plateau and a 489 weakening of rock once $\sigma_{2}$ exceeds a certain magnitude, which was verified experimentally by 490 Wiebols and Cook (1968) and later confirmed by other researchers (Mogi, 1971; Chang and 491 Haimson, 2000). Because the $\sigma_{2}$ effect predicted by the effective strain energy criterion excludes 492 the end effect, it can be considered as the "true" or the "actual" $\sigma_{2}$ effect.

All failure criteria have their limitations in representing the true physics of rock deformation under complex loading, and the effective strain energy criterion has with no 

517 reflect the actual $\sigma_{2}$ effect only.

exception. Laboratory test results show that the failure envelopes of rocks in conventional triaxial compression tests are normally nonlinear, especially near the brittle-ductile transition zones (Mogi, 1974), but the failure envelopes of conventional triaxial compression tests predicted by the effective strain energy criterion are linear. A precise prediction of a rock's failure envelope in the conventional triaxial stress state is the benchmark to ensure the accuracy of the predicted $\sigma_{1}-\sigma_{2}$ curve in the true triaxial stress state, because the conventional triaxial stress state is the origin of the $\sigma_{1}-\sigma_{2}$ curve. Acknowledging the shortcoming of the effective strain energy criterion, only the failure envelopes in the low confinement range will be considered. In addition, it is preferable to choose rocks whose $\sigma_{1}-\sigma_{3}$ relations in conventional triaxial compression tests are relatively linear. Another shortcoming of the effective strain energy criterion is that the $\mu_{\mathrm{s}}$ value is difficult to be determined. Wiebols and Cook (1968) provided failure envelopes for five $\mu_{\mathrm{s}}$ values $(0.25,0.5,0.667,0.85$, and 1) and pointed out that there is a relation between $\mu_{\mathrm{s}}$ and $\tan \phi$ (where $\mu_{\mathrm{s}}$ and $\tan \phi$ are close to each other but $\mu_{\mathrm{s}}<\tan \phi$ ). Accordingly, we choose the $\mu_{\mathrm{s}}$ value based on the $\tan \phi$ value of a rock.

The failure envelopes of KTB amphibolite with applied $\sigma_{3}$ ranging from 0 to $60 \mathrm{MPa}$ are used for validation. The calibrated $\phi$ values of KTB amphibolite in this applied $\sigma_{3}$ range (Table 3 ) are relatively constant compared with other rocks (Table 4 and Table 5), denoting relatively linear $\sigma_{1}-\sigma_{3}$ relations. Furthermore, the calibrated $\tan \phi$ in this $\sigma_{3}$ range is slightly higher than $\mu_{\mathrm{s}}$ $=1$. Therefore, the theoretical $\sigma_{2}$ effect predicted by the effective strain energy criterion for KTB amphibolite in the true triaxial compression tests can be obtained by assuming $\mu_{\mathrm{s}}=1$. Then, the influence of end effect on the observed $\sigma_{2}$ effect can be analyzed, by adding the modeling results, which quantify the end effect in the true triaxial compression tests, to the theoretical results that 
The combination of the numerical end effect and the theoretical $\sigma_{2}$ effect on rock strength

519 is shown in Fig. 17 and compared with the experimental test results, where $\sigma_{1}, \sigma_{2}$, and $\sigma_{3}$ are 520 normalized to $\sigma_{\mathrm{c}}$. The lower bound (dash line) corresponds to the theoretical result of Wiebols

521 and Cook (1968), which includes only the influence of $\sigma_{2}$ on rock strength for $\mu_{\mathrm{s}}=1$. The upper

522 bound (solid line) corresponds to the results of strength increase due to both the actual $\sigma_{2}$ effect

523 for $\mu_{\mathrm{s}}=1$ (according to Wiebols and Cook (1968)) and the end effect for $\mu=0.1$ (obtained from

524 our numerical modeling). Thus, the yellow highlighted zones between the upper bound and 525 lower bound of the $\sigma_{1}-\sigma_{2}$ curves represent the apparent $\sigma_{2}$ effect due to the end effect for a $\mu$ 526 value ranging from 0 to 0.1 .

Although there was strength variability in the test results of KTB amphibolite, most test data fell within the yellow highlighted zones, indicating that the end effect caused by $\sigma_{2}$ loading

529 somehow constituted part of the observed $\sigma_{2}$ effect. Because a laboratory test result inevitably contains an apparent $\sigma_{2}$ effect if the friction at the rock specimen-steel platen contacts is not zero,

$5313 \mathrm{D}$ empirical failure criteria developed from such a true triaxial compression test result may 532 overestimate the rock strength. Although the actual $\mu$ values in the previous laboratory tests were 533 unknown, our study shows that the end effect exists in true triaxial compression test for $\mu>0$ 534 and the $\mu$ values in those tests could range from 0.05 to 0.1 . Therefore, it is suggested that when 535 using previous and future true triaxial compression test results, the influence of the end effect on 536 the test results needs to be investigated. As illustrated in this study, with knowledge of the actual $537 \mu$ value at the rock specimen-steel platen contacts, the apparent $\sigma_{2}$ effect may be separated from 538 the observed $\sigma_{2}$ effect. In this way, the actual $\sigma_{2}$ effect could be characterized for the 539 development of 3D empirical failure criteria for rocks. 
540

541

542

543

544

545

546

547

548

549

550

551

552

553

554

555

556

557

558

559

562

560 with a very high machining accuracy, the specimen ends were ground flat and polished down to

$561 \pm 0.01 \mathrm{~mm}$. To prevent the anti-friction material from flowing into the rock specimen, a copper

\section{Recent laboratory work to minimize end effect and to characterize actual $\sigma_{2}$} effect

It was proposed in Section "Contribution of end effect to observed $\sigma_{2}$ effect" that with knowledge of the apparent $\sigma_{2}$ effect resulted by end constraint, it is possible to use previous true triaxial compression test data for the development of 3D empirical failure criteria of rocks. However, this approach should be applied individually to each laboratory test because the coefficients of friction at the rock specimen-steel platen contacts were not the same in the tests.

An alternative approach is to decrease the friction at the rock specimen-steel platen contacts to a level where the contribution of the end effect to the observed $\sigma_{2}$ effect is very small such that the obtained test data can be used directly to develop 3D empirical failure criteria. To achieve this goal, we must ensure that the end effect has been greatly reduced. Based on our modeling results, we conclude that the strengthening of rock strength due to the end effect for a $\mu$ value ranging from 0.05 to 0.1 cannot be neglected. Hence, the coefficient of friction at the rock specimen-steel platen contacts must be reduced to a value much less than 0.05 . In addition, the characteristics of the obtained test results should be somehow in accordance with that predicted by theoretical results (e.g., Wiebols and Cook, 1968). prepared using Linghai granite samples collected from a quarry site in Liaoning Province, China.

59 Linghai granite is homogeneous and isotropic with a high strength. Using a polishing machine

62 sheet of $0.02 \mathrm{~mm}$ thickness was put between the specimen and the platen. Then, friction tests 
563 with increasing normal forces were conducted to study the effectiveness of two anti-friction 564 measures, one by using Teflon and the other by using a mixture of stearic acid and Vaseline at a 565 1:1 ratio, recommended by Labuz and Bridell (1993). The black line in Fig. 18 shows the $\mu$ 566 values of the specimens' polished surfaces without lubricant. Because the specimens' end and 567 the platen's end surfaces had been polished smoothly, the obtained average $\mu$ value of 0.15 is 568 low, which is lower than that of some contacts smeared with lubricants (Section "Friction at rock 569 specimen-steel platen contacts"). The results shown in Fig. 18 clearly indicate that the mixture of 570 stearic acid and Vaseline at a 1:1 ratio in combination with a thin copper sheet can reduce the $\mu$ 571 value of the lubricated rock specimen-steel platen contact to about 0.02 . Referring to the 572 numerical simulation results in Section "Rock strength", it can be seen that the end effect caused 573 by $\mu=0.02$ is small and can be neglected.

True triaxial compression tests were conducted using a newly developed true triaxial 575 compression test apparatus (Feng et al., 2016). This novel test apparatus was designed and 576 fabricated on the basis of the Mogi-type apparatus with many improvements implemented to 577 address key issues such as off-center suppression, loading gap removal, and more importantly, 578 end effect reduction (Feng et al., 2016). Linghai granite specimens, with a rectangular prismatic 579 shape of $50 \times 50 \times 100 \mathrm{~mm}^{3}$, were used in the test. The effect of $\sigma_{2}$ on rock strength at low $\sigma_{3}$ 580 (up to $50 \mathrm{MPa}$ ) was focused in this laboratory test. The mixture of stearic acid and Vaseline at a 581 1:1 ratio and thin copper sheets were used to reduce friction at the contacts. Additionally, 582 compared with some previous true triaxial compression tests that barely reached the strength 583 plateau in the $\sigma_{1}-\sigma_{2}$ curves, the full range of $\sigma_{2}$ loading $\left(\sigma_{3} \leq \sigma_{2} \leq \sigma_{1}\right)$ was attempted to obtain 584 the complete $\sigma_{2}$ effect curves. The laboratory test results are shown in Fig. 19. 
The overall characteristics of the observed $\sigma_{2}$ effect on the strength of Linghai granite

agree with that of previous laboratory test results, showing an increase of rock strength with the increase of $\sigma_{2}$ before reaching the strength plateau and then a decrease of rock strength as $\sigma_{2}$ further increases. The complete strength drop from the strength plateau to the maximum loading range of $\sigma_{2}\left(\sigma_{2}=\sigma_{1}\right)$, a characteristic predicted by Wiebols and Cook (1968) but normally missed in some previous laboratory test results, was captured in this test. Additionally, we noticed a characteristic of the observed $\sigma_{2}$ effect on Linghai granite that differs from previous laboratory results. The $\sigma_{2}$ effect on rock strength as observed in previous test results is normally the greatest at low $\sigma_{3}$ and drastically decreased with the increase of $\sigma_{3}$ (Table 1); however, in the Linghai granite test results the rates of rock strength increase at the peak due to $\sigma_{2}$ are similar at different $\sigma_{3}$ (Table 7), which are about $51 \%$ to $56 \%$ in all cases. It is numerically proved in Sections "Rock strength" and "Contribution of end effect to observed $\sigma_{2}$ effect" that the apparent $\sigma_{2}$ effect resulted by the end constraint can lead to an overestimation of the actual $\sigma_{2}$ effect. On the other hand, the theoretical results (Wiebols and Cook, 1968) that exclude the end effect show a very small decrease of the peak strength increase due to $\sigma_{2}$ with the increase of $\sigma_{3}$ (Table 8 , with different $\mu_{\mathrm{s}}$ ). Therefore, these indirect evidences, supported by numerical and theoretical results, suggest that the anti-friction measure adopted in our tests is effective. In other words, the $\sigma_{2}$ effect shown in the test results is dominantly the actual $\sigma_{2}$ effect. The apparent $\sigma_{2}$ effect due to the end effect is small in our test results.

\section{End-effect-induced $\sigma_{2}$ effect at different $\sigma_{3}$ levels}

Based on previous discussions, the phenomenon of the drastic decrease of the $\sigma_{2}$ effect with the increase of $\sigma_{3}$ in the test results found in literature (Table 1) can be examined. The numerical 
607 experiment demonstrates that the end-effect-induced $\sigma_{2}$ effect decreases with the increase of $\sigma_{3}$ 608 (Fig. 7 to Fig. 10). Fig. 20 below illustrates how the end-effect-induced $\sigma_{2}$ effect is related to $\sigma_{3}$. 609 As explained in Section "Relation between the $\sigma_{2}$ effect and the increase of actual $\sigma_{3}$ ", the end 610 effect can increase the overall $\sigma_{3}$ of the specimen, making it higher than the applied $\sigma_{3}\left(\Delta \sigma_{3}\right)$. In 611 other words, the end-effect-induced $\sigma_{2}$ effect (pink coordinate systems) is manifested by the 612 increase of $\Delta \sigma_{3}$ with the increase of $\sigma_{2}$, and that in turn leads to the increase of rock strength $613\left(\Delta \sigma_{1}\right)$. In the numerical modeling, the end-effect-induced $\sigma_{2}$ effect depends on the friction angle 614 when the M-C failure criterion is used. The higher the friction angle is, the greater the end-effect615 induced $\sigma_{2}$ effect will be.

616 The friction angle calibrated (Table 3 to Table 6) decreases with the increase of $\sigma_{3}$ (blue 617 and green dash lines) and this matches well the nonlinearity of the $\sigma_{1}-\sigma_{3}$ failure envelopes (grey 618 curve). Therefore, all the modeling results with various $\mu$ values reflect that the end-effect619 induced $\sigma_{2}$ effect decreases with the increase of $\sigma_{3}$. Note that the $\sigma_{1}-\sigma_{3}$ failure envelope 620 representing conventional triaxial compression tests (grey coordinate system) is plotted in Fig. 621 20. This is because that true triaxial compression tests $\left(\sigma_{2} \geq \sigma_{3}\right)$ normally begin with a stress 622 state of $\sigma_{2}=\sigma_{3}$; true triaxial compression test results are obtained by increasing $\sigma_{2}$ from the 623 applied $\sigma_{3}$. 627 envelope. On the other hand, at very high $\sigma_{3}$ levels, the calibrated friction angle can overestimate 628 the slope of the failure envelope. Hence, the simulation results (Fig. 7d) at intermediate $\sigma_{3}$ levels 
629

630

631

632

633

634

635

636

637

638

639

640

641

642

643

644

645

646

647

648

649

650

651

match laboratory test results well (green dash lines), while at very low and very high $\sigma_{3}$ levels the modeling results are not equally good.

We consider that as long as the trend of the end-effect-induced $\sigma_{2}$ effect revealed from the numerical modeling confirms our research hypothesis (the end-effect-induced $\sigma_{2}$ effect is large), there is no need to require that the modeling results match the test results perfectly. In fact, a perfect match between the modeling results and the test results can only suggest that the $\sigma_{2}$ effect observed in the laboratory test results are completely caused by the end effect. This implication is not correct because both theoretical and laboratory studies have shown that there is a legit $\sigma_{2}$ effect to rock strength. More importantly, the differences between the modeling and the test results at very low and very high $\sigma_{3}$ levels support the viewpoint: the end effect affects true triaxial compression test results; the $\sigma_{2}$ effect decrease with the increase of $\sigma_{3}$.

It was experimentally confirmed by Mogi (2007) that rock strength increase due to the end effect increases with the decrease of $\sigma_{3}$. Hence, it can be interpreted that in the previous laboratory test results, the end-effect-induced rock strength increase was high when the applied $\sigma_{3}$ was low, which resulted in a greater apparent $\sigma_{2}$ effect. The end effect became smaller at high applied $\sigma_{3}$. Fig. 21 presents some conventional triaxial compression test results of rocks and their H-B fitting curves. Nonlinearity of the failure envelopes is observed ubiquitously in these rocks, illustrating that the same end-effect-induced $\Delta \sigma_{3}$ at a low $\sigma_{3}$ can result in a greater increase of rock strength $\Delta \sigma_{1}$ than that at a high $\sigma_{3}$. Therefore, the end effect can result in a large apparent $\sigma_{2}$ effect when $\sigma_{3}$ is low and the observed $\sigma_{2}$ effect at low $\sigma_{3}$ in some previous test results might be exaggerated. It is suggested that if true triaxial compression test results contain an unknown influence of end effect on rock strength, the test results at high $\sigma_{3}$, which are less influenced by the end effect, might be more appropriate for developing 3D empirical failure criteria for rocks. 


\section{Conclusions}

653 Laboratory test results show that the use of lubricants cannot eliminate the end effect completely,

654 especially when the rock specimen is squat in the $\sigma_{2}$ loading direction. The influence of end 655 effect on rock strength in true triaxial compression test is studied using a numerical approach.

656 The influence of $\sigma_{2}$ on rock strength is purposely excluded in the material model in the 657 numerical study so that any increase of rock strength with the increase of $\sigma_{2}$ while the applied $\sigma_{3}$

658 is kept constant can be attributed to the end effect. It is seen from the simulation results that 659 friction at the rock specimen-steel platen contacts has a large influence on rock strength, because 660 the $\sigma_{3}$ in the specimen is increased due to the end constraint at the $\sigma_{2}$ loading contacts. Thus, the 661 end effect can result in an apparent $\sigma_{2}$ effect that contributes to the observed strength increase 662 due to $\sigma_{2}$ in true triaxial compression tests. This point can explain why some rocks show the $\sigma_{2}$ 663 effect while others do not because different end constraints can be initiated by different rock 664 deformation behaviors. This study made a contribution to better understanding true triaxial 665 compression test results by decomposing the observed $\sigma_{2}$ effect on rock strength in laboratory 666 tests into two parts: one from the end effect and the other from the actual $\sigma_{2}$ effect. The actual $\sigma_{2}$ 667 effect can be explained using the theory of Wiebols and Cook (1968).

668 Considering that the end effect can result in an apparent $\sigma_{2}$ effect that may mislead the 669 interpretation of the true triaxial compression test results, some suggestions are made for future 670 study of the $\sigma_{2}$ effect. Firstly, previous laboratory test results are still useful in developing 3D 671 empirical failure criteria for rocks. An improvement can be made by employing a reverse 672 strategy to subtract the apparent $\sigma_{2}$ effect from the observed $\sigma_{2}$ effect, provided that the actual 673 end effect in the true triaxial compression test results can be quantified. Otherwise, one can refer 
674 to the test results obtained at high $\sigma_{3}$, where the relative influence by the end effect is small. 675 According to our recent laboratory work and supported by the numerical and theoretical results, 676 it is seen that previous test results that showed a significant $\sigma_{2}$ effect at low $\sigma_{3}$ might include a 677 large end effect. Hence, future study should focus on quantifying the actual $\sigma_{2}$ effect under low 678 confinement conditions because it is important for rock engineering practices. Moreover, when 679 conducting true triaxial compression test to study the $\sigma_{2}$ effect, attention should be paid to 680 minimizing the end effect. Our recent laboratory work shows that using a novel test apparatus 681 and effective anti-friction measures, the end effect can be decreased to minimize the apparent $\sigma_{2}$ 682 effect such that the characteristics of the obtained $\sigma_{2}$ effect are very close to the true $\sigma_{2}$ effect.

Note that the conclusions drawn here are based on the numerical simulation results using

684 a homogeneous model. Material heterogeneity of rocks may influence the failure modes. Using 685 heterogeneous models, researchers have found that $\sigma_{2}$ has a small influence on rock strength (Cai, 686 2008b) when $\sigma_{3}=0$ and $\sigma_{2}$ is not high. Thus, future work needs to consider the heterogeneity of 687 rock properties to quantify the end effect on rock strength in true triaxial compression tests.

\section{Acknowledgements}

689 This work was financially supported by NSERC (Natural Science and Engineering Research 690 Council of Canada) and the Open Research Fund of the State Key Laboratory of Geomechanics 691 and Geotechnical Engineering, Institute of Rock and Soil Mechanics, Chinese Academy of 692 Sciences (Grant NO. Z015001).

\section{References}


Al-Ajmi, A.M., and Zimmerman, R.W. 2005. Relation between the Mogi and the Coulomb failure criteria. International Journal of Rock Mechanics and Mining Sciences.;42:431-9.

Babcock, C.O. Effect of increasing end constraint on the compressive strength of model rock pillars. US Dept. of the Interior, Bureau of Mines; 1969.

Bhat, H., Sammis, C., and Rosakis, A. 2011. The micromechanics of westerley granite at large compressive loads. Pure and Applied Geophysics 168:2181-98.

Bieniawski, Z, and Bernede, M. 1979. Suggested methods for determining the uniaxial compressive strength and deformability of rock materials: Part 1. Suggested method for determining deformability of rock materials in uniaxial compression. International Journal of Rock Mechanics and Mining Sciences \& Geomechanics Abstracts 16:138-40.

Brady, B. 1971. Effects of inserts on the elastic behavior of cylindrical materials loaded between rough end-plates. International Journal of Rock Mechanics and Mining Sciences \& Geomechanics Abstracts 8:357-69.

Brady, B.H., and Brown, E.T. Rock mechanics: for underground mining: Springer Science \& Business Media; 2013.

Brown, E. Estimating the mechanical properties of rock masses. Proceedings of the 1st southern hemisphere international rock mechanics symposium: SHIRMS2008. p. 3-21.

Cai, M. 2008a. Influence of stress path on tunnel excavation response-numerical tool selection and modeling strategy. Tunnelling and Underground Space Technology 23:618-28.

Cai, M. 2008b. Influence of intermediate principal stress on rock fracturing and strength near excavation boundaries-insight from numerical modeling. International Journal of Rock Mechanics and Mining Sciences 45:763-72.

Cai, M., and Kaiser, P. 2014. In-situ rock spalling strength near excavation boundaries. Rock mechanics and rock engineering 47:659-75.

Chang, C., and Haimson, B. 2000. True triaxial strength and deformability of the German Continental Deep Drilling Program (KTB) deep hole amphibolite. Journal of Geophysical Research: Solid Earth 105:18999-9013.

Chang, C., and Haimson, B. 2005. Non-dilatant deformation and failure mechanism in two Long Valley Caldera rocks under true triaxial compression. International Journal of Rock Mechanics and Mining Sciences 42:402-14.

Choi, S., Thienel, K-C., and Shah, S. 1996. Strain softening of concrete in compression under different end constraints. Magazine of Concrete Research 48:103-15.

Colmenares, L., and Zoback, M. A. 2002. Statistical evaluation of intact rock failure criteria constrained by polyaxial test data for five different rocks. International Journal of Rock Mechanics and Mining Sciences 39:695-729. 
Dai, F., Huang, S., Xia, K., and Tan, Z. 2010. Some fundamental issues in dynamic compression and tension tests of rocks using split Hopkinson pressure bar. Rock mechanics and rock engineering 43:657-66.

Eberhardt, E. 2012. The Hoek-Brown Failure Criterion. Rock Mechanics and Rock Engineering 45:981-8.

Fang, Z., and Harrison, J.P. 2001. A mechanical degradation index for rock. International Journal of Rock Mechanics and Mining Sciences 38:1193-9.

Feng, X-T., Zhang, X., Kong, R., Wang, G. 2016. A Novel Mogi Type True Triaxial Testing Apparatus and Its Use to Obtain Complete Stress-Strain Curves of Hard Rocks. Rock Mechanics and Rock Engineering 1-14.

Fjær, E., and Ruistuen, H. 2002. Impact of the intermediate principal stress on the strength of heterogeneous rock. Journal of Geophysical Research: Solid Earth 107.

Gaffney, E. 1976. Measurements of dynamic friction between rock and steel. Defense Nuclear Agency.

Gercek, H. 2007. Poisson's ratio values for rocks. International Journal of Rock Mechanics and Mining Sciences 44:1-13.

Gerstle, K.B., Zimmerman, R.M., Winkler, H., Traina, L.A., Taylor, M.A., Schickert G, et al. 1980. Behavior of concrete under multiaxial stress states. Journal of the Engineering Mechanics Division 106:1383-403.

Gerstle, K.H., Linse, D.L., and Bertacchi, P. 1978. Strength of concrete under multiaxial stress states. ACI Special Publication 55.

Grote, K-H., and Antonsson, E.K. 2009. Springer handbook of mechanical engineering: Springer Science \& Business Media.

Haimson, B., Chang, C. A new true triaxial cell for testing mechanical properties of rock, and its use to determine rock strength and deformability of Westerly granite. International Journal of Rock Mechanics and Mining Sciences. 2000;37:285-96.

Haimson, B.C., and Chang, C. 2002. True triaxial strength of the KTB amphibolite under borehole wall conditions and its use to estimate the maximum horizontal in situ stress. Journal of Geophysical Research: Solid Earth (1978-2012) 107:ETG 15-1-ETG -4.

Hajiabdolmajid, V., Kaiser, P., and Martin, C. 2002. Modelling brittle failure of rock. International Journal of Rock Mechanics and Mining Sciences 39:731-41.

Hawkes, I., and Mellor, M. 1970. Uniaxial testing in rock mechanics laboratories. Engineering Geology 4:179-285. 
He, H., Shi, L., and Bai, B. 2014. The effect of the true triaxial test subjected to different loading types on end friction. Journal of Transport Science and Engineering (in Chinese) 30:1-5.

He, M., Miao, J., and Feng, J. 2010. Rock burst process of limestone and its acoustic emission characteristics under true-triaxial unloading conditions. International Journal of Rock Mechanics and Mining Sciences 47:286-98.

Hemami, B., and Fakhimi, A. 2014. Numerical Simulation of Rock-Loading Machine Interaction. 48th US Rock Mechanics/Geomechanics Symposium: American Rock Mechanics Association.

Hoek, E. 2007. Practical Rock Engineering. 2007: Online. ed. Rocscience.

Hoek, E., and Brown, E. 1997. Practical estimates of rock mass strength. International Journal of Rock Mechanics and Mining Sciences.;34:1165-86.

Hoek, E., Carranza-Torres, C., and Corkum, B. 2002. Hoek-Brown failure criterion-2002 edition. Proceedings of NARMS-Tac. p. 267-73.

Hoskins, J.R., and Horino, F.G. 1968. Effect of end conditions on determining compressive strength of rock samples. US Dept. of the Interior, Bureau of Mines.

Hudson, J.A., Harrison, J.P. 2000. Engineering rock mechanics-an introduction to the principles: Elsevier

Hudson, J.A., Crouch, S.L., and Fairhurst, C. 1972. Soft, stiff and servo-controlled testing machines: a review with reference to rock failure. Engineering Geology.;6:155-89.

Jaeger, J.C., Cook, N.G., and Zimmerman, R. 2007. Fundamentals of rock mechanics: John Wiley \& Sons.

Kias, E., and Ozbay, U. 2013. Modeling unstable failure of coal pillars in underground mining using the discrete element method. 47th US Rock Mechanics/Geomechanics Symposium: American Rock Mechanics Association.

Kotsovos, M. 1983. Effect of testing techniques on the post-ultimate behaviour of concrete in compression. Materiaux Et Construction 16:3-12.

Labuz, J., and Bridell, J. 1993. Reducing frictional constraint in compression testing through lubrication. International Journal of Rock Mechanics and Mining Sciences \& Geomechanics Abstracts 30:451-5.

Labuz, J.F., and Zang, A. 2012. Mohr-Coulomb failure criterion. Rock Mechanics and Rock Engineering 1-5.

Li, X., Du, K., and Li, D. 2015. True Triaxial Strength and Failure Modes of Cubic Rock Specimens with Unloading the Minor Principal Stress. Rock Mechanics and Rock Engineering.:1-12. 
Liang, C., Zhang, Q., Li, X., and Xin, P. 2015. The effect of specimen shape and strain rate on uniaxial compressive behavior of rock material. Bulletin of Engineering Geology and the Environment 1-13.

Lockner, D.A. 1998. A generalized law for brittle deformation of Westerly granite. Journal of Geophysical Research: Solid Earth (1978-2012) 103:5107-23.

Martin, C.D. 1997. Seventeenth Canadian geotechnical colloquium: the effect of cohesion loss and stress path on brittle rock strength. Canadian Geotechnical Journal 34:698-725.

Meikle, P., and Holland, C. 1965. The effect of friction on the strength of model coal pillars. Trans Soc Mining Eng. 232:322-7.

Michelis, P. 1987. True triaxial cyclic behavior of concrete and rock in compression. International Journal of Plasticity 3:249-70.

Mogi, K. 1967. Effect of the intermediate principal stress on rock failure. Journal of Geophysical Research 72:5117-31.

Mogi, K. 1971. Fracture and flow of rocks under high triaxial compression. Journal of Geophysical Research 76:1255-69.

Mogi, K. 1974. On the pressure dependence of strength of rocks and the Coulomb fracture criterion. Tectonophysics 21:273-85.

Mogi, K. 2007. Experimental rock mechanics: CRC Press.

Pariseau, W. 2007. Fitting failure criteria to laboratory strength tests. International Journal of Rock Mechanics and Mining Sciences 44:637-46.

Pellegrino, A., Sulem, J., and Barla, G. 1997. The effects of slenderness and lubrication on the uniaxial behavior of a soft limestone. International Journal of Rock Mechanics and Mining Sciences 34:333-40.

Potyondy, D., and Cundall, P. 2004. A bonded-particle model for rock. International journal of rock mechanics and mining sciences 41:1329-64.

Rashed, G., Peng, S.S. 2015. Change of the mode of failure by interface friction and width-toheight ratio of coal specimens. Journal of Rock Mechanics and Geotechnical Engineering.

Read, H., and Hegemier, G. 1984. Strain softening of rock, soil and concrete - a review article. Mechanics of Materials 3:271-94.

Renner, J., and Rummel, F. 1996. The effect of experimental and microstructural parameters on the transition from brittle failure to cataclastic flow of carbonate rocks. Tectonophysics 258:151-69. 
Schöpfer, M.P., Childs, C., and Manzocchi, T. 2013. Three - dimensional failure envelopes and the brittle - ductile transition. Journal of Geophysical Research: Solid Earth 118:1378-92.

Senent, S., Jimenez, R., and Reyes, A. 2013. Numerical simulation of the influence of smallscale defects on the true-triaxial strength of rock samples. Computers and Geotechnics $53: 142-56$.

Shi, L., Li, X., Bai, B., Li, Q., and Feng, X. 2012. Numerical analysis of loading boundary effects in Mogi-type true triaxial tests. In: Kwaśniewski M, Li X, Takahashi M, editors. True triaxial testing of rocks. Leiden, the Netherlands: CRC Press p. 19-34.

Takahashi, M., and Koide, H. 1989. Effect of the intermediate principal stress on strength and deformation behavior of sedimentary rocks at the depth shallower than $2000 \mathrm{~m}$. ISRM international symposium: International Society for Rock Mechanics.

Tang, C., Tham, L., Lee, P., Tsui, Y., and Liu, H. 2000. Numerical studies of the influence of microstructure on rock failure in uniaxial compression-part II: constraint, slenderness and size effect. International Journal of Rock Mechanics and Mining Sciences 37:571-83.

Van Vliet, M., and Van Mier, J. 1996. Experimental investigation of concrete fracture under uniaxial compression. Mechanics of Cohesive - frictional Materials 1:115-27.

Vutukuri, V.S., Lama, R.D., and Saluja, S.S. 1974. Handbook on Mechanical Properties of Rocks: Testing Techniques \& Results: Trans Tech Publications.

Wiebols, G., and Cook, N. 1968. An energy criterion for the strength of rock in polyaxial compression. International Journal of Rock Mechanics and Mining Sciences \& Geomechanics Abstracts 5:529-49.

$\mathrm{Xu}$, Y., and Cai, M. 2015. Numerical Simulation of End Constraint Effect on Post-peak Behaviors of Rocks in Uniaxial Compression. 49th US Rock Mechanics/Geomechanics Symposium. San Francisco, USA.

Xu, Y., Dai, F., Zhao, T., Xu, N-w., and Liu, Y. 2016. Fracture Toughness Determination of Cracked Chevron Notched Brazilian Disc Rock Specimen via Griffith Energy Criterion Incorporating Realistic Fracture Profiles. Rock Mechanics and Rock Engineering 1-11.

You, M. 2009. True-triaxial strength criteria for rock. International Journal of Rock Mechanics and Mining Sciences 46:115-27.

Zhao, X., and Cai, M. 2010. A mobilized dilation angle model for rocks. International Journal of Rock Mechanics and Mining Sciences 47:368-84.

Zhao, X., Cai, M., and Wang, G. 2012. Acoustic emission behaviors of the Beishan granite under uniaxial and triaxial compression conditions. Dynamic Web Programming and HTML5:75. 
862 Zhao, X., Cai, M., Wang, J., and Ma, L. 2013. Damage stress and acoustic emission 863 characteristics of the Beishan granite. International Journal of Rock Mechanics and Mining 864 Sciences 64:258-69.

865

866 
Fig. 1. Schematic of the proposed method to quantify $\sigma_{2}$ effect.

Fig. 2. Illustration of confined zones due to end effect in specimens with different slenderness ratios in rock uniaxial compression tests, after Van Vliet and Van Mier (1996).

Fig. 3. Illustration of the shape and the corresponding end effect in true triaxial compression test.

Fig. 4. 3D models of three types of compression tests in numerical experiment: (a) uniaxial compression test, (b) conventional triaxial compression test, (c) true triaxial compression test.

Fig. 5 FEM models of rock specimens and loading platens for different compression test simulations: (a) uniaxial and triaxial, and (b) true triaxial.

Fig. 6. Simulation of the deformation behavior of Westerly granite under confinement of $\sigma_{2}$ $=\sigma_{3}=60 \mathrm{MPa}$.

Fig. 7. Simulation of true triaxial compression tests of KTB amphibolite: (a) $\mu=0$, (b) $\mu=$ 0.05 , (c) $\mu=0.1$, (d) $\mu=0.2$.

Fig. 8. Simulation of true triaxial compression tests of Westerly granite: (a) $\mu=0$, (b) $\mu=$ 0.05 , (c) $\mu=0.1$, (d) $\mu=0.2$.

Fig. 9. Simulation of true triaxial compression tests of Solnhofen limestone: (a) $\mu=0$, (b) $\mu$ $=0.05$, (c) $\mu=0.1$, (d) $\mu=0.2$.

Fig. 10. Simulation of true triaxial compression tests of Yuubari shale: (a) $\mu=0$, (b) $\mu=$ 0.05, (c) $\mu=0.1$, (d) $\mu=0.2$.

Fig. 11. Numerical and laboratory (Chang andHaimson, 2000)-results of typical failure modes of a KTB amphibolite specimen.

Fig. 12. Numerical and laboratory (Haimson and Chang, 2000)-results of typical failure modes of a Westerly granite specimen.

Fig. 13. Numerical and laboratory (Mogi, 2007)-results of typical failure modes of a Solnhofen limestone specimen.

Fig. 14. Resultant displacements at peak load on the plane cutting through the mid-height of the Westerly granite specimens.

Fig. $15 . \sigma_{3}$ contours in the Westerly granite specimens at peak load.

Fig. 16. Deviatoric stress-volumetric strain curves for: (a) KTB amphibolite and (b) Long Valley Caldera metapelite in true triaxial compression tests (digitized and modified from Chang and Haimson, 2000 and Chang and Haimson, 2005, respectively).

Fig. 17. Combination of numerical end effect and theoretical $\sigma_{2}$ effect on rock strength, compared with the experimental data of KTB amphibolite. 
$902 \quad$ Fig. 18. $\mu$ values of rock specimen-steel platen contacts measured by shear tests with 903 different normal forces.

904 Fig. 19. Laboratory true triaxial compression test results showing the $\sigma_{2}$ effect on the 905 strength of Linghai granite.

906 Fig. 20. Comparison of end-effect-induced $\sigma_{2}$ effect (refer to the pink coordinate system) at 907 different applied $\sigma_{3}$ levels (refer to the grey coordinate system).

908 Fig. 21. Conventional triaxial compression test results of some rocks and their $H$-B fitting 909 curves: (a) KTB amphibolite, (b) Westerly granite, (c) Solnhofen limestone, (d) Yuubari 910 shale (Takahashi and Koide, 1989; Chang and Haimson, 2000; Haimson and Chang, 2000; 911 Mogi, 2007). 
Table 1. Quantified $\sigma_{2}$ effect in different rocks (data from Chang and Haimson, 2000; Haimson and Chang, 2000; Mogi, 2007).

\begin{tabular}{|c|c|c|c|c|c|c|c|}
\hline \multirow{2}{*}{$\begin{array}{l}\text { KTB } \\
\text { amphibolite }\end{array}$} & $\sigma_{3} / \sigma_{\mathrm{c}}$ & 0.00 & 0.19 & 0.38 & 0.63 & 0.95 & \\
\hline & $\left(\sigma_{1}^{*}-\sigma_{1}\right) /\left(\sigma_{2}{ }^{*}-\sigma_{2}\right)$ & $69 \%$ & $70 \%$ & $39 \%$ & $45 \%$ & $29 \%$ & \\
\hline \multirow{2}{*}{$\begin{array}{l}\text { Westerly } \\
\text { granite }\end{array}$} & $\sigma_{3} / \sigma_{\mathrm{c}}$ & 0.00 & 0.10 & 0.19 & 0.30 & 0.38 & 0.50 \\
\hline & $\left(\sigma_{1}{ }^{*}-\sigma_{1}\right) /\left(\sigma_{2}{ }^{*}-\sigma_{2}\right)$ & $114 \%$ & $103 \%$ & $88 \%$ & $59 \%$ & $49 \%$ & $58 \%$ \\
\hline \multirow{2}{*}{$\begin{array}{l}\text { Dunham } \\
\text { dolomite }\end{array}$} & $\sigma_{3} / \sigma_{\mathrm{c}}$ & 0.09 & 0.17 & 0.25 & 0.32 & 0.40 & 0.47 \\
\hline & $\left(\sigma_{1}{ }^{*}-\sigma_{1}\right) /\left(\sigma_{2}{ }^{*}-\sigma_{2}\right)$ & $78 \%$ & $63 \%$ & $43 \%$ & $42 \%$ & $38 \%$ & $32 \%$ \\
\hline \multirow{2}{*}{$\begin{array}{l}\text { Solnhofen } \\
\text { limestone }\end{array}$} & $\sigma_{3} / \sigma_{\mathrm{c}}$ & 0.06 & 0.13 & 0.26 & & & \\
\hline & $\left(\sigma_{1}{ }^{*}-\sigma_{1}\right) /\left(\sigma_{2}{ }^{*}-\sigma_{2}\right)$ & $34 \%$ & $33 \%$ & $36 \%$ & & & \\
\hline \multirow{2}{*}{$\begin{array}{l}\text { Yamaguchi } \\
\text { marble }\end{array}$} & $\sigma_{3} / \sigma_{\mathrm{c}}$ & 0.15 & 0.30 & 0.49 & & & \\
\hline & $\left(\sigma_{1}{ }^{*}-\sigma_{1}\right) /\left(\sigma_{2}{ }^{*}-\sigma_{2}\right)$ & $104 \%$ & $79 \%$ & $53 \%$ & & & \\
\hline \multirow{2}{*}{$\begin{array}{l}\text { Mizuho } \\
\text { trachyte }\end{array}$} & $\sigma_{3} / \sigma_{\mathrm{c}}$ & 0.45 & 0.60 & 0.75 & 1.00 & & \\
\hline & $\left(\sigma_{1}{ }^{*}-\sigma_{1}\right) /\left(\sigma_{2}{ }^{*}-\sigma_{2}\right)$ & $34 \%$ & $30 \%$ & $26 \%$ & $25 \%$ & & \\
\hline \multirow{2}{*}{$\begin{array}{l}\text { Manazuru } \\
\text { andesite }\end{array}$} & $\sigma_{3} / \sigma_{\mathrm{c}}$ & 0.14 & 0.29 & 0.50 & & & \\
\hline & $\left(\sigma_{1}{ }^{*}-\sigma_{1}\right) /\left(\sigma_{2}{ }^{*}-\sigma_{2}\right)$ & $82 \%$ & $54 \%$ & $52 \%$ & & & \\
\hline \multirow{2}{*}{$\begin{array}{l}\text { Inada } \\
\text { granite }\end{array}$} & $\sigma_{3} / \sigma_{\mathrm{c}}$ & 0.09 & 0.18 & 0.44 & 0.66 & 0.88 & \\
\hline & $\left(\sigma_{1}{ }^{*}-\sigma_{1}\right) /\left(\sigma_{2}{ }^{*}-\sigma_{2}\right)$ & $104 \%$ & $71 \%$ & $57 \%$ & $65 \%$ & $69 \%$ & \\
\hline \multirow{2}{*}{$\begin{array}{l}\text { Orikabe } \\
\text { monzonite }\end{array}$} & $\sigma_{3} / \sigma_{\mathrm{c}}$ & 0.17 & 0.34 & 0.59 & 0.85 & & \\
\hline & $\left(\sigma_{1}{ }^{*}-\sigma_{1}\right) /\left(\sigma_{2}{ }^{*}-\sigma_{2}\right)$ & $115 \%$ & $80 \%$ & $66 \%$ & $67 \%$ & & \\
\hline
\end{tabular}

Table 2. Physical and deformation parameters of the rocks.

\begin{tabular}{lcccc}
\hline Rock types & $\begin{array}{c}\text { Density } \\
\left(\mathbf{k g} / \mathbf{m}^{\mathbf{3}}\right)\end{array}$ & $\begin{array}{c}\text { Young's modulus } \\
(\mathbf{G P a})\end{array}$ & $\begin{array}{c}\text { Poisson's } \\
\text { ratio }\end{array}$ & References \\
\hline KTB amphibolite & 2920 & 65 & 0.29 & $\begin{array}{c}\text { Haimson and } \\
\text { Chang (2002) }\end{array}$ \\
\hline Westerly granite & 2700 & 60 & 0.28 & $\begin{array}{c}\text { Bhat et al. } \\
(2011)\end{array}$ \\
\hline Solnhofen limestone & 2500 & 80 & 0.20 & $\begin{array}{c}\text { Renner and } \\
\text { Rummel } \\
(1996)\end{array}$ \\
\hline Yuubari shale & 2200 & 40 & 0.20 & \begin{tabular}{c} 
Gercek (2007) \\
\hline
\end{tabular} \\
\hline
\end{tabular}


Table 3. Calculation of the M-C strength parameters of KTB amphibolite (data from Colmenares and Zoback, 2002, original data from Chang and Haimson, 2000).

\begin{tabular}{|c|c|c|c|c|}
\hline $\begin{array}{c}\sigma_{3} \text { level } \\
(\mathrm{MPa})\end{array}$ & $\begin{array}{c}\text { Data }\left(\sigma_{1}, \sigma_{2}=\sigma_{3}\right) \\
(\mathrm{MPa})\end{array}$ & Fitting equation & $\begin{array}{c}\text { Cohesion } \\
(\mathrm{MPa})\end{array}$ & $\begin{array}{c}\text { Friction angle } \\
\left({ }^{\circ}\right)\end{array}$ \\
\hline 0 & $\begin{array}{l}(158,0) \\
(176,0) \\
(410,30)\end{array}$ & $\sigma_{1}=8.4 \sigma_{3}+176$ & 31 & 52 \\
\hline 30 & $\begin{array}{l}(158,0) \\
(410,30) \\
(702,60)\end{array}$ & $\sigma_{1}=9.1 \sigma_{3}+151$ & 26 & 53 \\
\hline 60 & $\begin{array}{l}(410,30) \\
(702,60) \\
(868,100)\end{array}$ & $\sigma_{1}=6.4 \sigma_{3}+318$ & 62 & 47 \\
\hline 100 & $\begin{array}{l}(410,30) \\
(702,60) \\
(868,100) \\
(1147,150) \\
\end{array}$ & $\sigma_{1}=6.2 \sigma_{3}+232$ & 48 & 46.5 \\
\hline 150 & $\begin{array}{l}(868,100) \\
(1147,150)\end{array}$ & $\sigma_{1}=5.6 \sigma_{3}+310$ & 66 & 44 \\
\hline
\end{tabular}

Table 4. Calculation of the M-C strength parameters of Westerly granite (data from AlAjmi and Zimmerman, 2005, digitized from Haimson and Chang, 2000).

\begin{tabular}{|c|c|c|c|c|}
\hline $\begin{array}{l}\sigma_{3} \text { level } \\
(\mathrm{MPa})\end{array}$ & $\begin{array}{c}\text { Data }\left(\sigma_{1}, \sigma_{2}=\sigma_{3}\right) \\
(\mathrm{MPa})\end{array}$ & Fitting equation & $\begin{array}{c}\text { Cohesion } \\
\text { (MPa) }\end{array}$ & $\begin{array}{c}\text { Friction angle } \\
\left({ }^{\circ}\right)\end{array}$ \\
\hline 0 & $\begin{array}{l}(201,0) \\
(231,2)\end{array}$ & $\sigma_{1}=15.0 \sigma_{3}+201$ & 26 & 61 \\
\hline 20 & $\begin{array}{l}(201,0) \\
(430,20) \\
(605,38)\end{array}$ & $\sigma_{1}=10.7 \sigma_{3}+206$ & 33 & 56 \\
\hline 38 & $\begin{array}{l}(430,20) \\
(605,38) \\
(747,60)\end{array}$ & $\sigma_{1}=7.9 \sigma_{3}+306$ & 54 & 51 \\
\hline 60 & $\begin{array}{l}(605,38) \\
(747,60) \\
(889,77) \\
\end{array}$ & $\sigma_{1}=7.3 \sigma_{3}+325$ & 60 & 49 \\
\hline 77 & $\begin{array}{l}(747,60) \\
(889,77) \\
(1012,100) \\
\end{array}$ & $\sigma_{1}=6.6 \sigma_{3}+385$ & 76 & 47 \\
\hline 100 & $\begin{array}{l}(889,77) \\
(1012,100)\end{array}$ & $\sigma_{1}=5.4 \sigma_{3}+477$ & 101 & 44 \\
\hline
\end{tabular}


Table 5. Calculation of the M-C strength parameters of Solnhofen limestone (data from Mogi, 2007).

\begin{tabular}{|c|c|c|c|c|}
\hline $\begin{array}{c}\sigma_{3} \text { level } \\
(\mathrm{MPa})\end{array}$ & $\begin{array}{c}\text { Data }\left(\sigma_{1}, \sigma_{2}=\sigma_{3}\right) \\
(\mathrm{MPa})\end{array}$ & Fitting equation & $\begin{array}{c}\text { Cohesion } \\
\text { (MPa) }\end{array}$ & $\begin{array}{c}\text { Friction angle } \\
\left({ }^{\circ}\right)\end{array}$ \\
\hline 20 & $\begin{array}{l}(310,0) \\
(397,20) \\
(449,40)\end{array}$ & $\sigma_{1}=3.5 \sigma_{3}+328$ & 88 & 34 \\
\hline 40 & $\begin{array}{l}(310,0) \\
(397,20) \\
(449,40)\end{array}$ & $\sigma_{1}=3.5 \sigma_{3}+316$ & 84 & 34 \\
\hline $\begin{array}{c}60 \\
*\end{array}$ & $\begin{array}{l}(310,0) \\
(397,20) \\
(449,40) \\
(473,60) \\
\end{array}$ & $\sigma_{1}=2.7 \sigma_{3}+326$ & 98 & 28 \\
\hline 80 & $\begin{array}{l}(473,60) \\
(528,80)\end{array}$ & $\sigma_{1}=2.8 \sigma_{3}+308$ & 93 & 28 \\
\hline \multicolumn{5}{|c|}{$\begin{array}{l}\text { * Conventional triaxial compression test data at } \sigma_{3}=60 \mathrm{MPa} \text { diverges somewhat from the failure } \\
\text { envelop; hence, calibration of the friction angle was adjusted accordingly. } \\
\text { Table 6. Calculation of the M-C strength parameters of Yuubari shale (data from } \\
\text { Colmenares and Zoback, 2002, digitized from Takahashi and Koide, 1989). }\end{array}$} \\
\hline $\begin{array}{l}\sigma_{3} \text { level } \\
(\mathrm{MPa})\end{array}$ & $\begin{array}{c}\text { Data }\left(\sigma_{1}, \sigma_{2}=\sigma_{3}\right) \\
(\mathrm{MPa})\end{array}$ & Fitting equation & $\begin{array}{l}\text { Cohesion } \\
\text { (MPa) }\end{array}$ & $\begin{array}{c}\begin{array}{c}\text { Friction angle } \\
\left({ }^{\circ}\right)\end{array} \\
\end{array}$ \\
\hline 25 & $\begin{array}{l}(161,25) \\
(228,50)\end{array}$ & $\sigma_{1}=2.7 \sigma_{3}+94$ & 29 & 27 \\
\hline 50 & $\begin{array}{l}(161,25) \\
(228,50)\end{array}$ & $\sigma_{1}=2.7 \sigma_{3}+94$ & 29 & 27 \\
\hline
\end{tabular}

Table 7. Quantified $\sigma_{2}$ effect on Linghai granite.

\begin{tabular}{|l|l|l|l|l|l|}
\hline$\sigma_{3} / \sigma_{\mathrm{c}}$ & 0.00 & 0.06 & 0.12 & 0.18 & 0.31 \\
\hline$\left(\sigma_{1}{ }^{*}-\sigma_{1}\right) /\left(\sigma_{2}{ }^{*}-\sigma_{2}\right)$ & $56 \%$ & $52 \%$ & $52 \%$ & $53 \%$ & $51 \%$ \\
\hline
\end{tabular}


Table 8. Quantified $\sigma_{2}$ effect predicted by the theory of Wiebols and Cook (1968) for different $\mu_{\mathrm{s}}$.

\begin{tabular}{|l|l|l|l|l|l|l|}
\hline \multirow{3}{*}{$\mu_{\mathrm{s}}=0.25$} & $\sigma_{3} / \sigma_{\mathrm{c}}$ & 0.00 & 0.20 & 0.40 & 0.60 & 0.80 \\
\cline { 2 - 6 } & $\left(\sigma_{1}{ }^{*}-\sigma_{1}\right) /\left(\sigma_{2}{ }^{*}-\sigma_{2}\right)$ & $44 \%$ & $43 \%$ & $43 \%$ & $43 \%$ & $43 \%$ \\
\hline \multirow{3}{*}{$\mu_{\mathrm{s}}=0.50$} & $\sigma_{3} / \sigma_{\mathrm{c}}$ & 0.00 & 0.10 & 0.20 & 0.30 & 0.40 \\
\cline { 2 - 7 } & $\left(\sigma_{1}{ }^{*}-\sigma_{1}\right) /\left(\sigma_{2}{ }^{*}-\sigma_{2}\right)$ & $67 \%$ & $66 \%$ & $65 \%$ & $64 \%$ & $64 \%$ \\
\hline \multirow{3}{*}{$\mu_{\mathrm{s}}=0.67$} & $\sigma_{3} / \sigma_{\mathrm{c}}$ & 0.00 & 0.05 & 0.10 & 0.15 & 0.20 \\
\cline { 2 - 7 } & $\left(\sigma_{1}{ }^{*}-\sigma_{1}\right) /\left(\sigma_{2}{ }^{*}-\sigma_{2}\right)$ & $79 \%$ & $78 \%$ & $77 \%$ & $75 \%$ & $74 \%$ \\
\hline \multirow{3}{*}{$\mu_{\mathrm{s}}=0.80$} & $\sigma_{3} / \sigma_{\mathrm{c}}$ & 0.00 & 0.05 & 0.10 & 0.15 & 0.20 \\
\cline { 2 - 7 } & $\left(\sigma_{1}{ }^{*}-\sigma_{1}\right) /\left(\sigma_{2}{ }^{*}-\sigma_{2}\right)$ & $87 \%$ & $83 \%$ & $80 \%$ & $79 \%$ & $78 \%$ \\
\hline \multirow{2}{*}{$\mu_{\mathrm{s}}=1.00$} & $\sigma_{3} / \sigma_{\mathrm{c}}$ & 0.00 & 0.05 & 0.10 & 0.15 & 0.20 \\
\cline { 2 - 7 } & $\left(\sigma_{1}{ }^{*}-\sigma_{1}\right) /\left(\sigma_{2}{ }^{*}-\sigma_{2}\right)$ & $101 \%$ & $88 \%$ & $83 \%$ & $81 \%$ & $79 \%$ \\
\hline
\end{tabular}




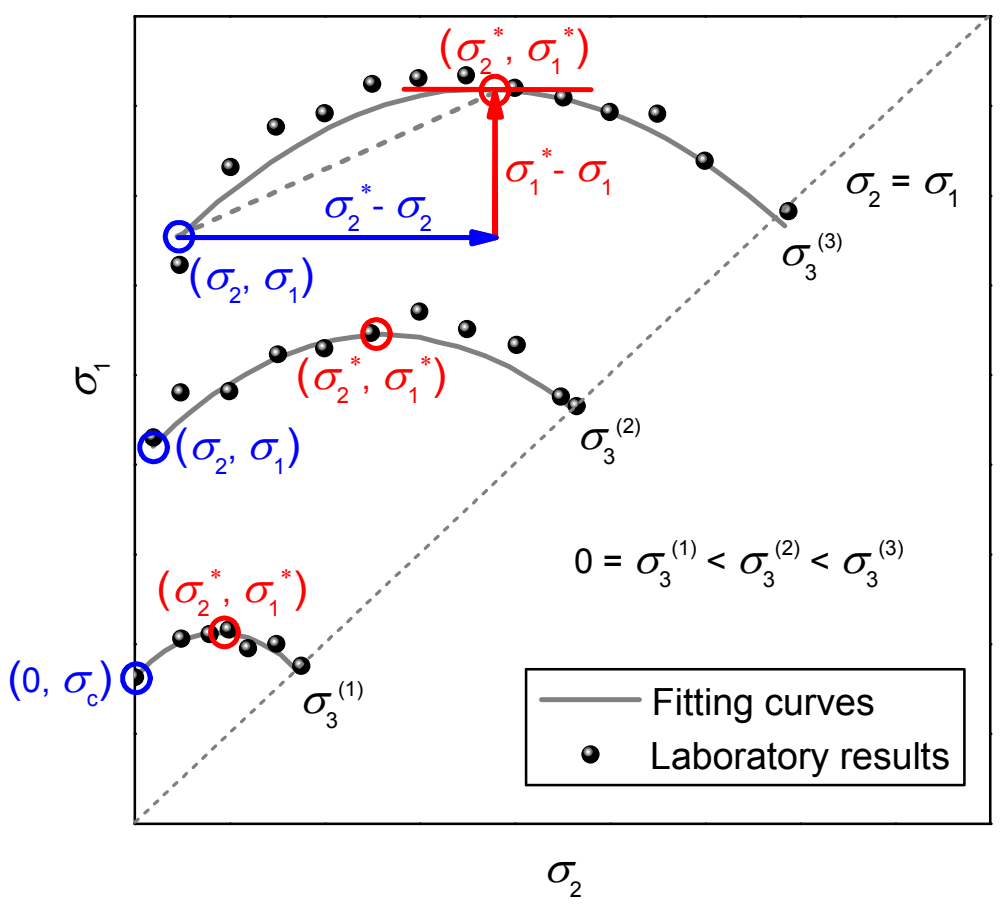

Figure 1. Schematic of the proposed method to quantify $\sigma_{2}$ effect.
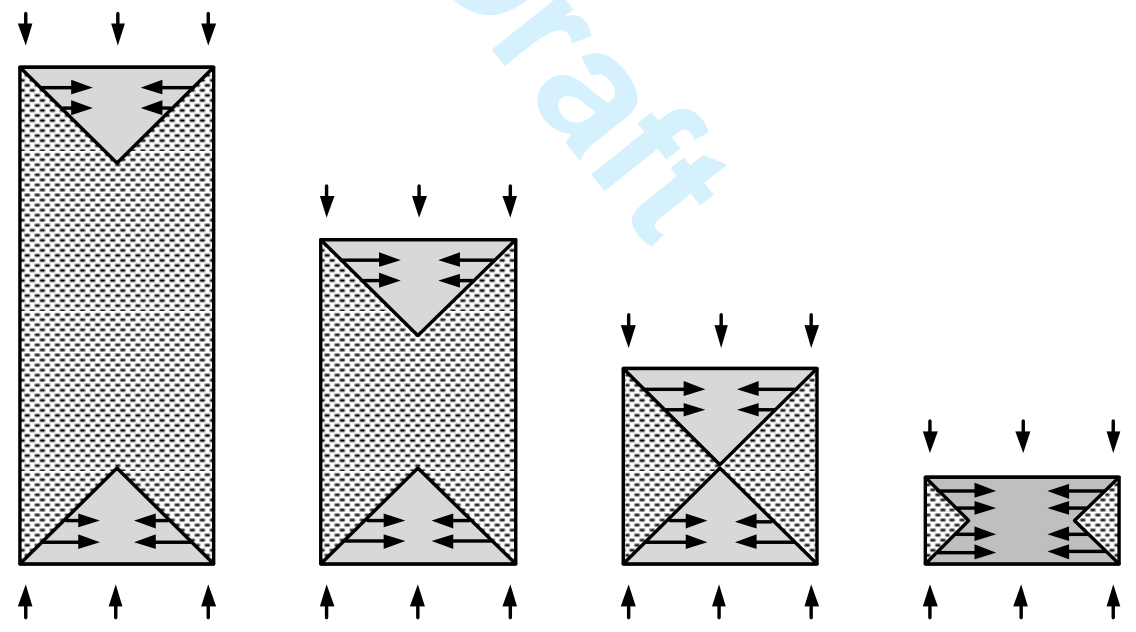

Figure 2. Illustration of confined zones due to end effect in specimens with different slenderness ratios in rock uniaxial compression tests, after Van Vliet and Van Mier (1996). 

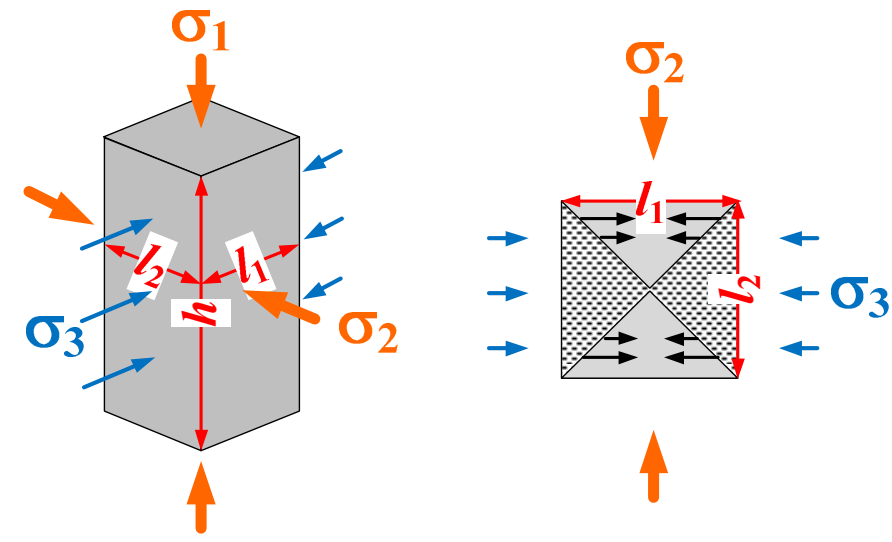

Figure 3. Illustration of the shape and the corresponding end effect in true triaxial compression test. 

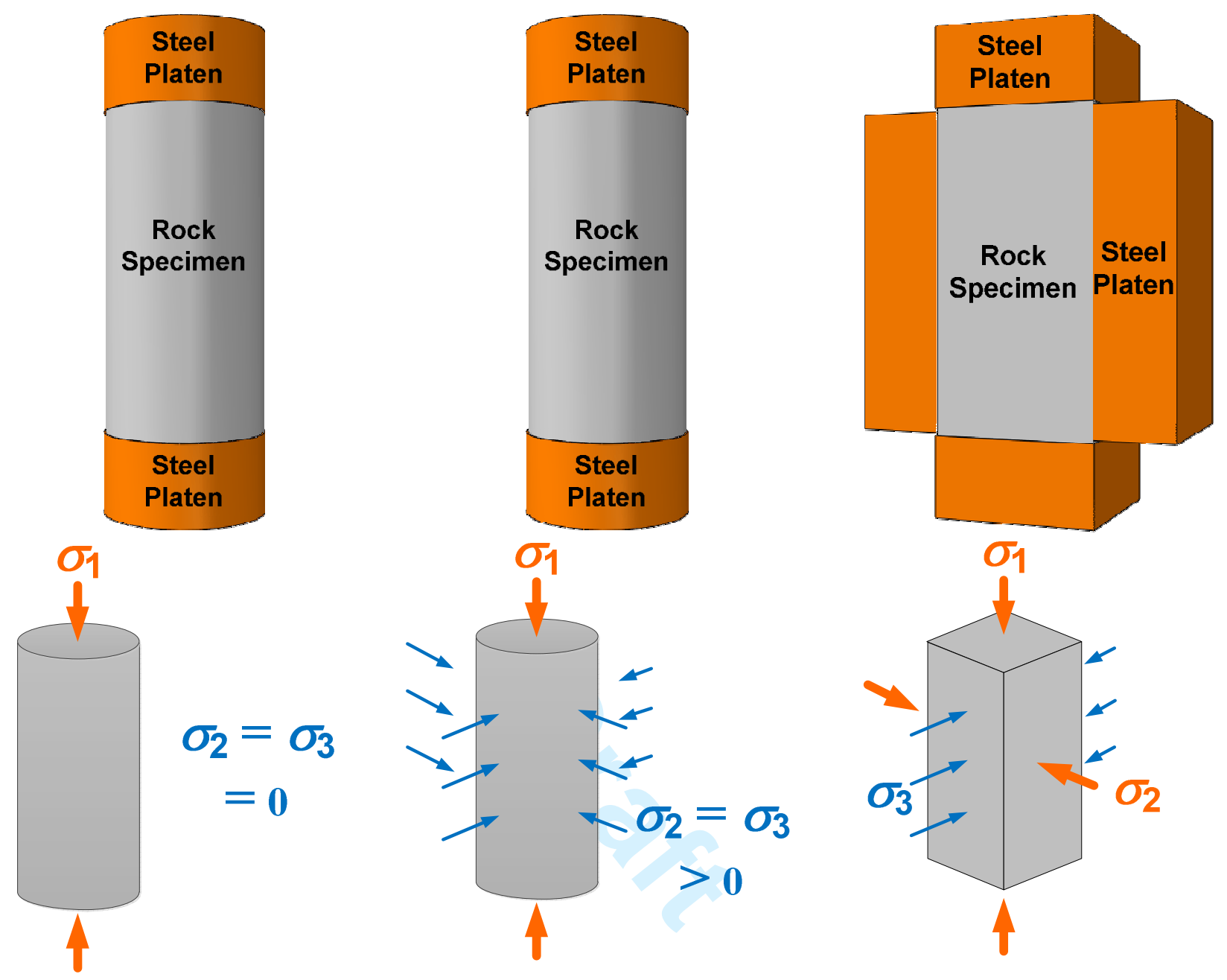

(a)

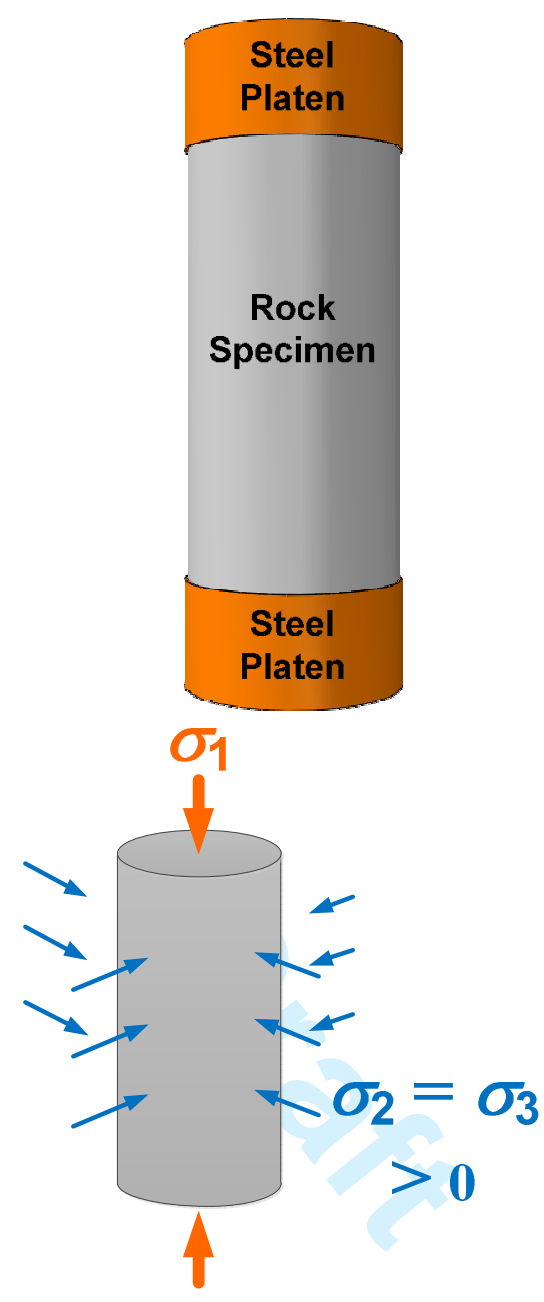

(b)

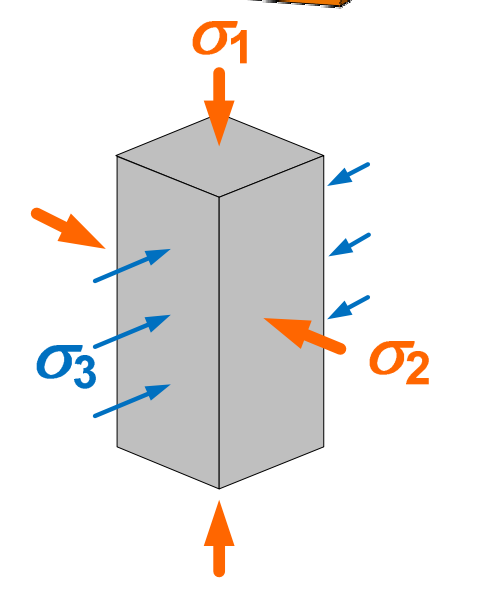

(c)

Figure 4. 3D models of three types of compression tests in numerical experiment: (a) uniaxial compression test, (b) conventional triaxial compression test, (c) true triaxial compression test. 


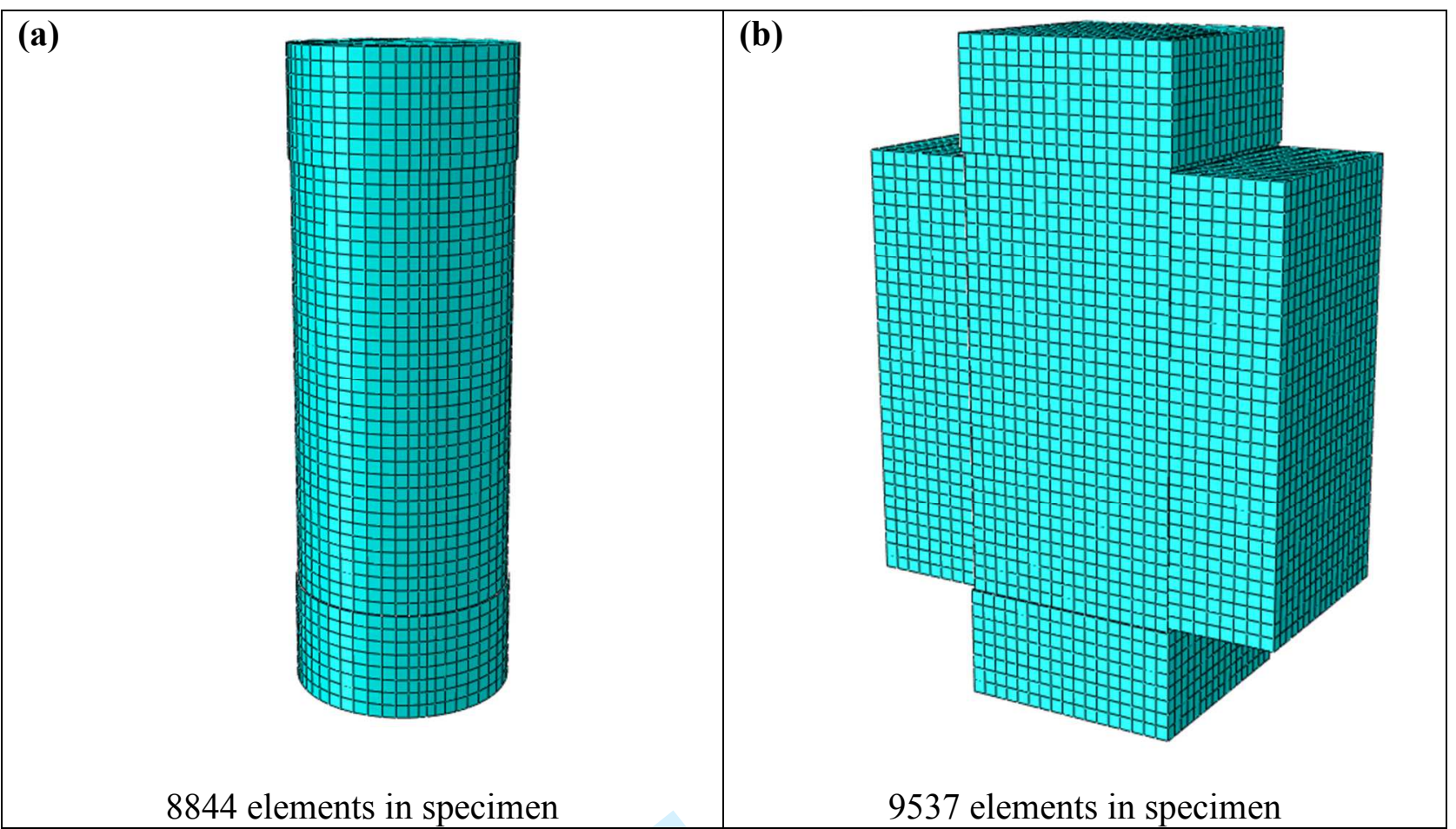

Figure 5 FEM models of rock specimens and loading platens for different compression test simulations: (a) uniaxial and triaxial, and (b) true triaxial.

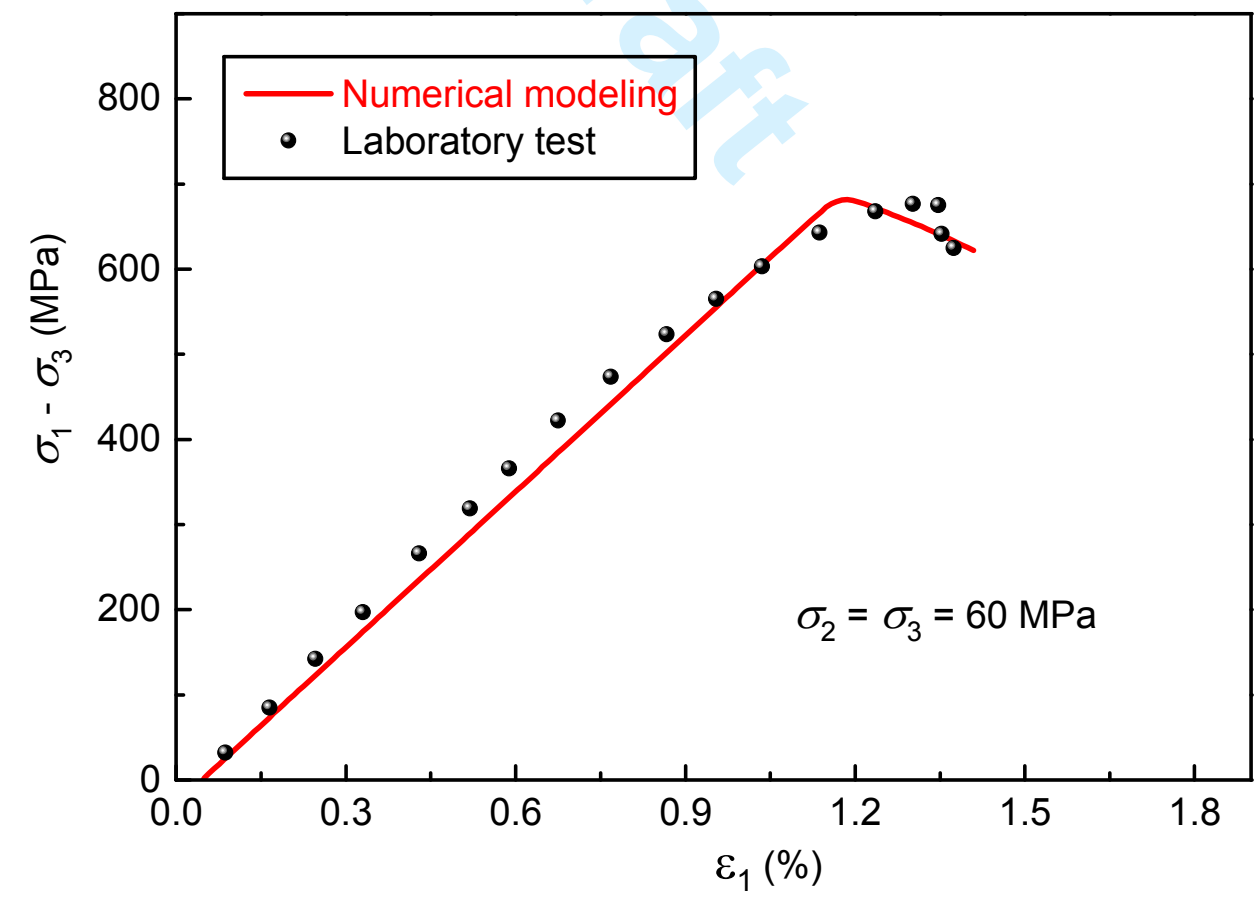

Figure 6. Simulation of the deformation behavior of Westerly granite under confinement of $\sigma_{2}=\sigma_{3}=60 \mathrm{MPa}$. 
- Laboratory results - - Modeling results $\left(\sigma_{2}=\sigma_{3}\right) \quad$ Modeling results $\left(\sigma_{2}>\sigma_{3}\right)$
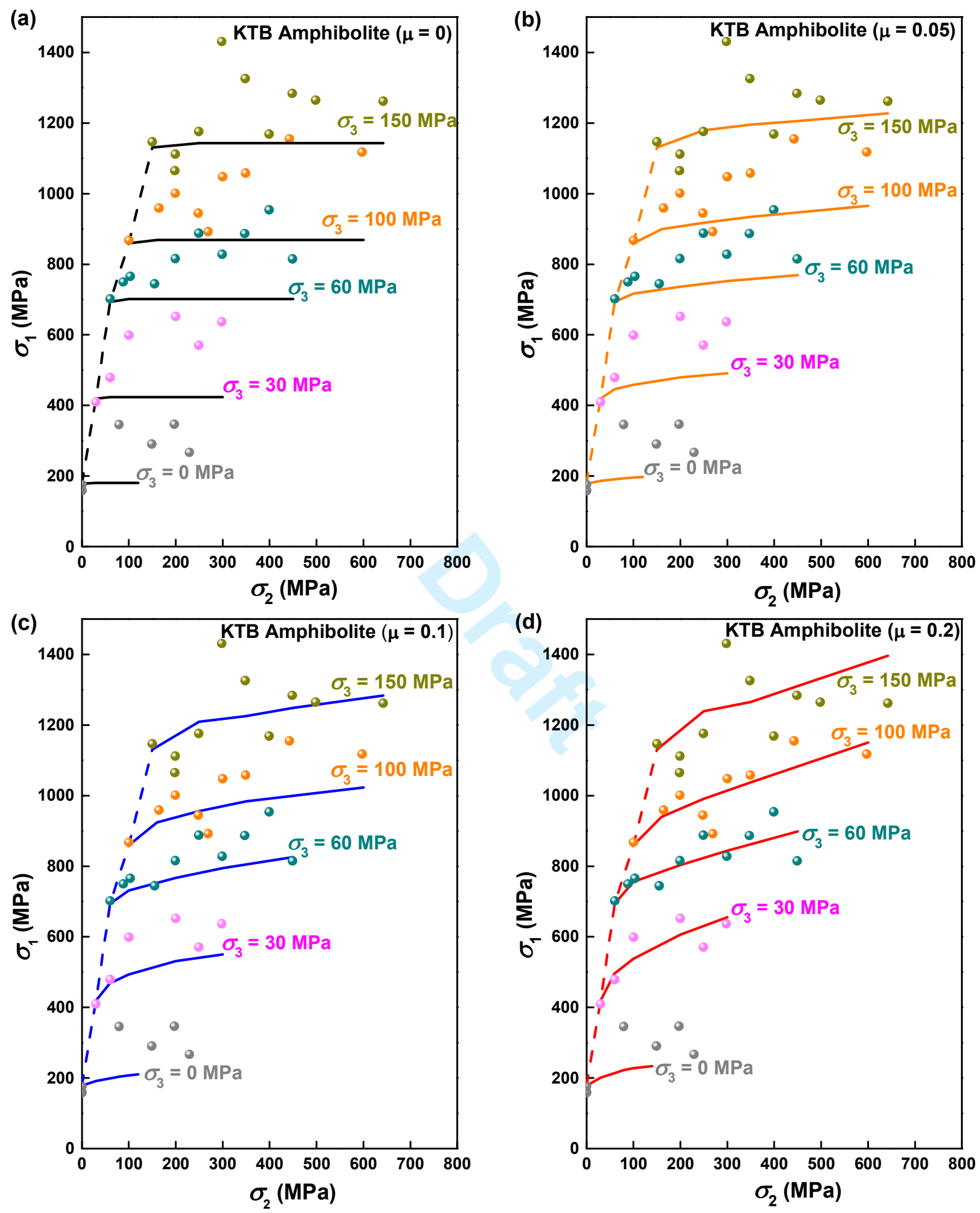

Figure 7. Simulation of true triaxial compression tests of KTB amphibolite: (a) $\mu=0$, (b) $\mu$ $=0.05$, (c) $\mu=0.1$, (d) $\mu=0.2$. 
- Laboratory results - - Modeling results $\left(\sigma_{2}=\sigma_{3}\right) \quad$ Modeling results $\left(\sigma_{2}>\sigma_{3}\right)$
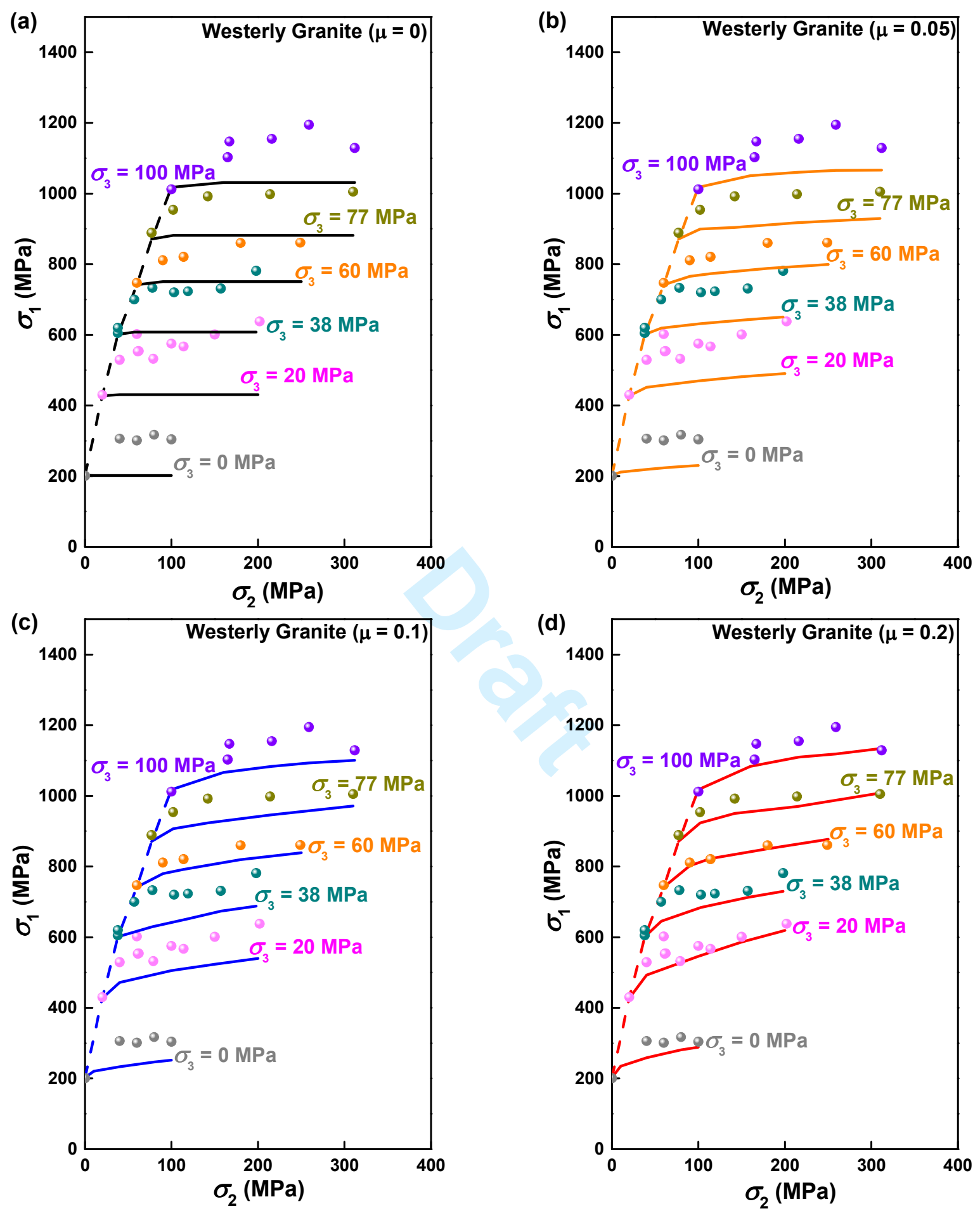

Figure 8. Simulation of true triaxial compression tests of Westerly granite: (a) $\mu=0$, (b) $\mu=$ 0.05 , (c) $\mu=0.1$, (d) $\mu=0.2$. 
- Laboratory results - - Modeling results $\left(\sigma_{2}=\sigma_{3}\right) \quad$ Modeling results $\left(\sigma_{2}>\sigma_{3}\right)$
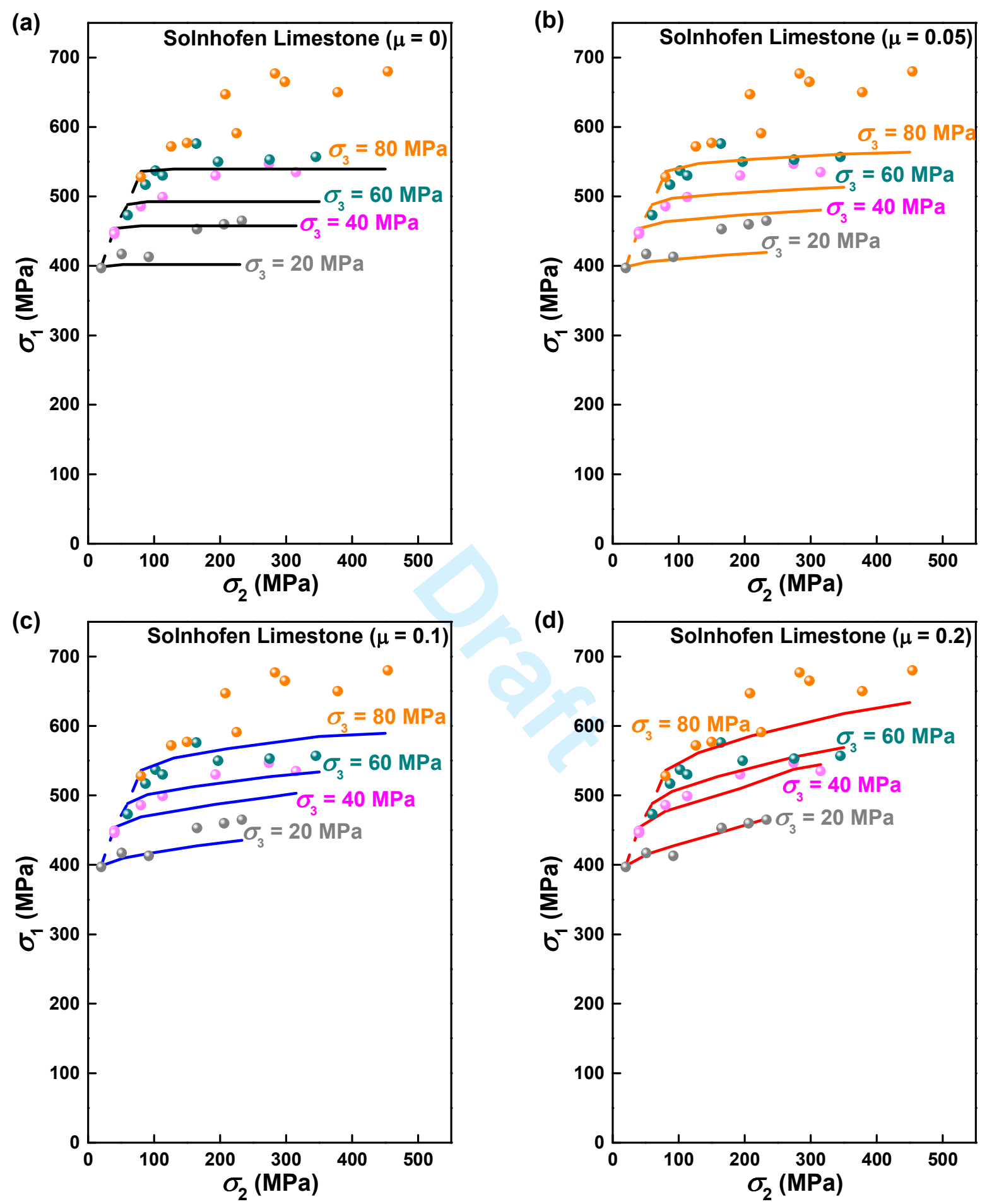

Figure 9. Simulation of true triaxial compression tests of Solnhofen limestone: (a) $\mu=0$, (b) $\mu=0.05$, (c) $\mu=0.1$, (d) $\mu=0.2$. 
(a)
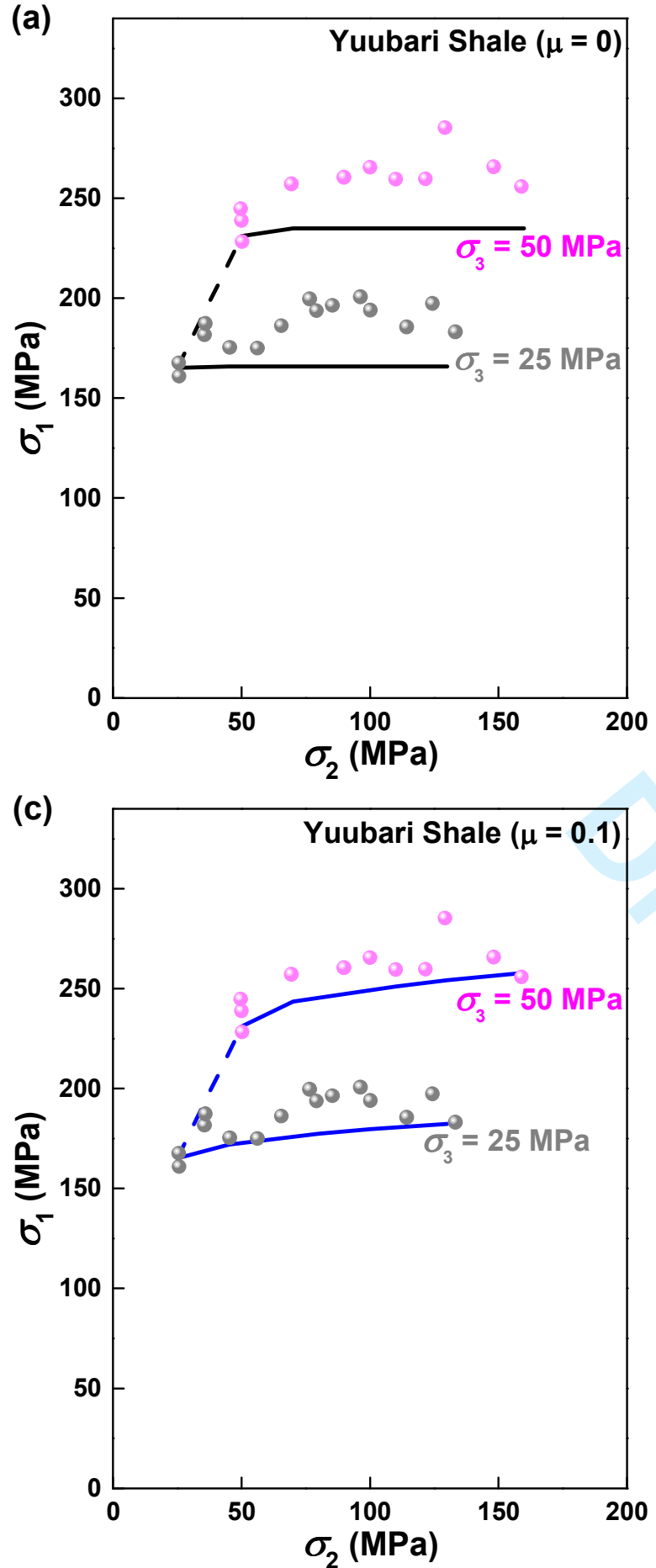

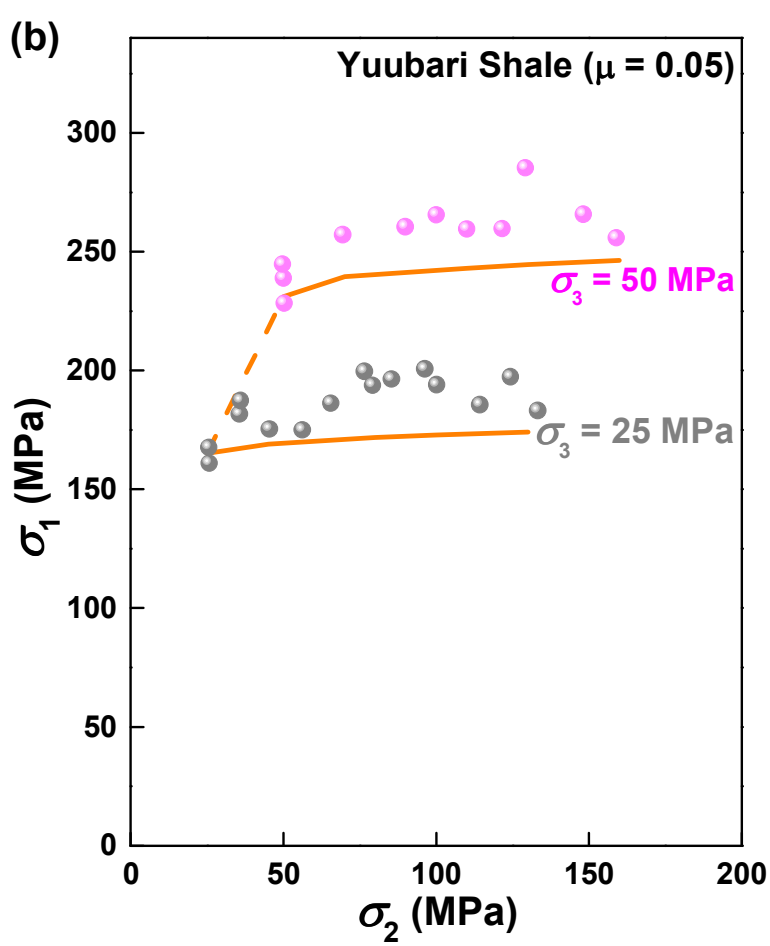

(d)

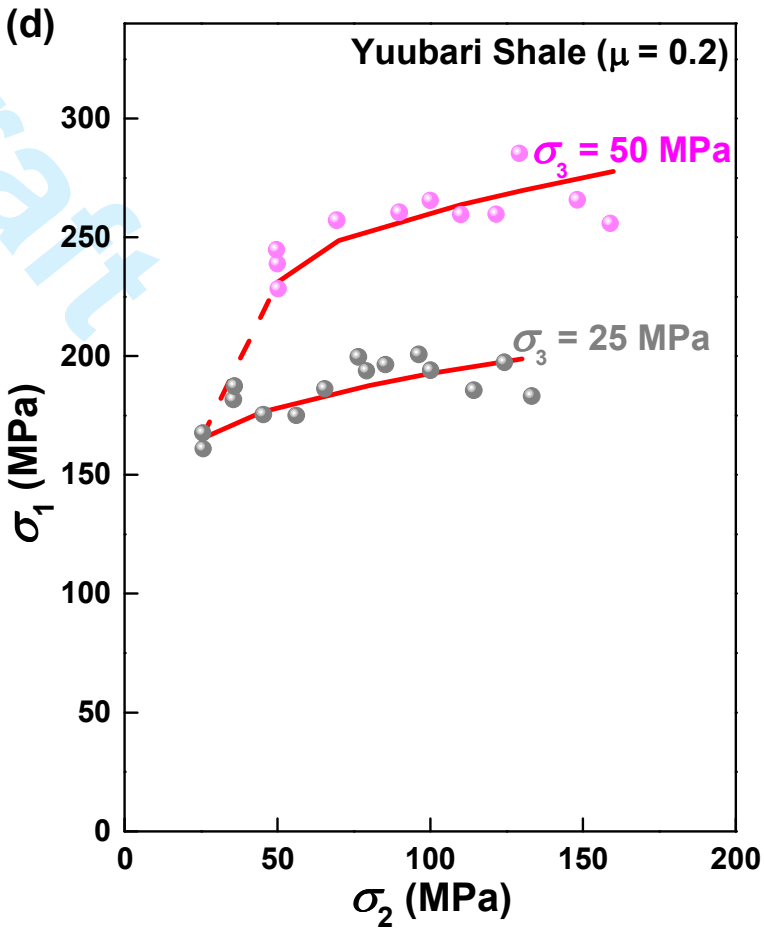

Figure 10. Simulation of true triaxial compression tests of Yuubari shale: (a) $\mu=0$, (b) $\mu=$ 0.05 , (c) $\mu=0.1$, (d) $\mu=0.2$. 


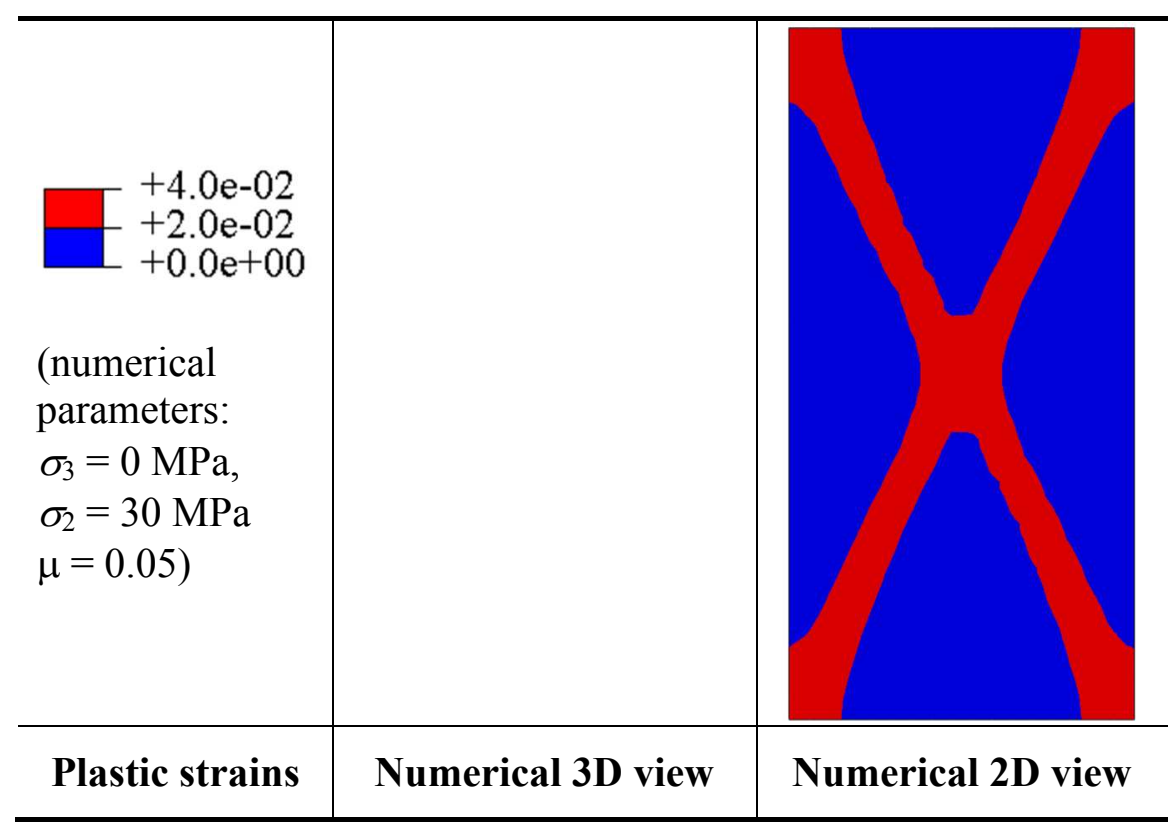

Figure 11. Numerical and Haboratory (Chang and Haimson, 2000)-results of typical failure modes of a KTB amphibolite specimen.

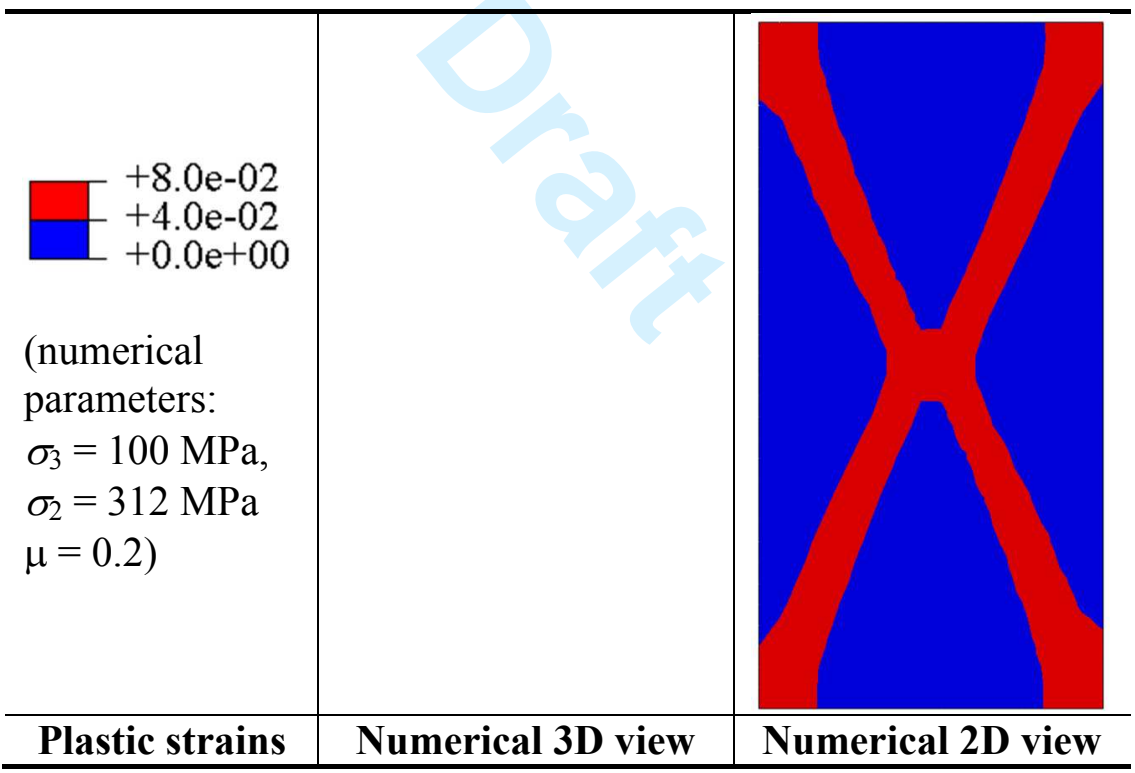

Figure 12. Numerical and laboratory (Haimson and Chang, 2000)-results of typical failure modes of a Westerly granite specimen. 


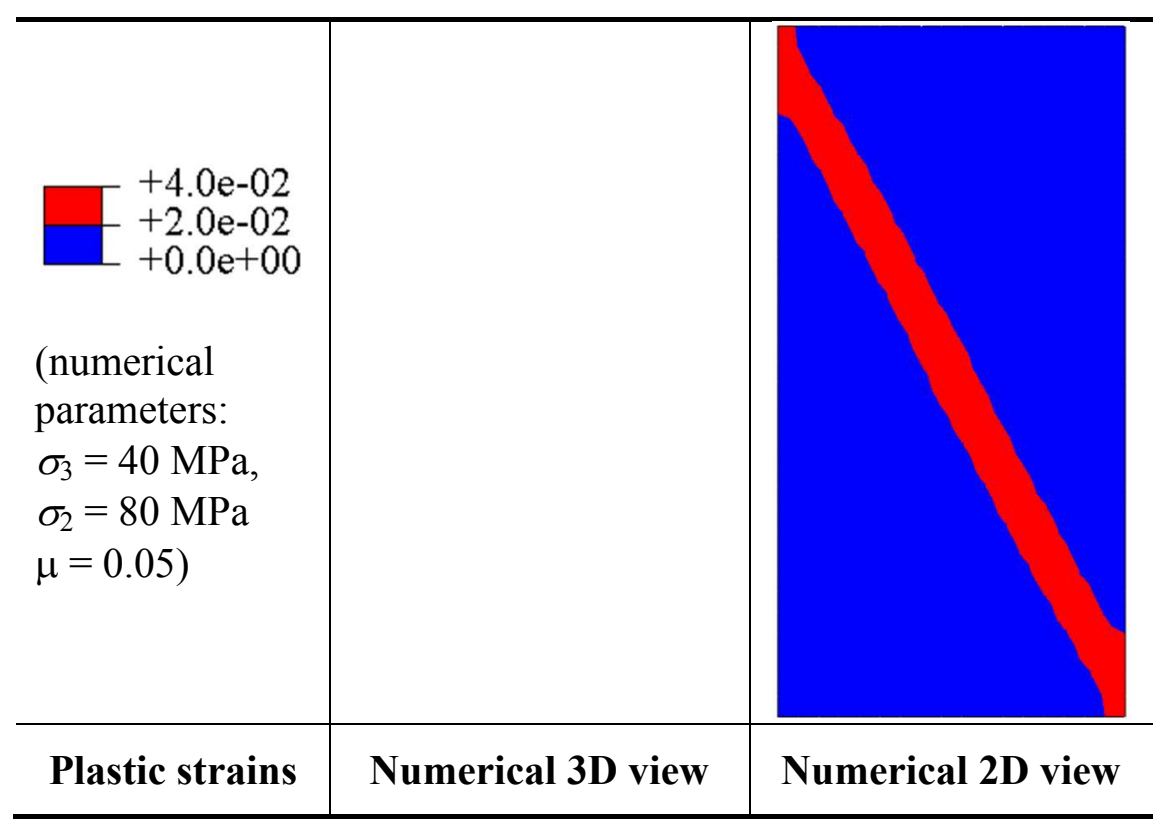

Figure 13. Numerical and laboratory (Mogi, 2007)-results of typical failure modes of a Solnhofen limestone specimen. 


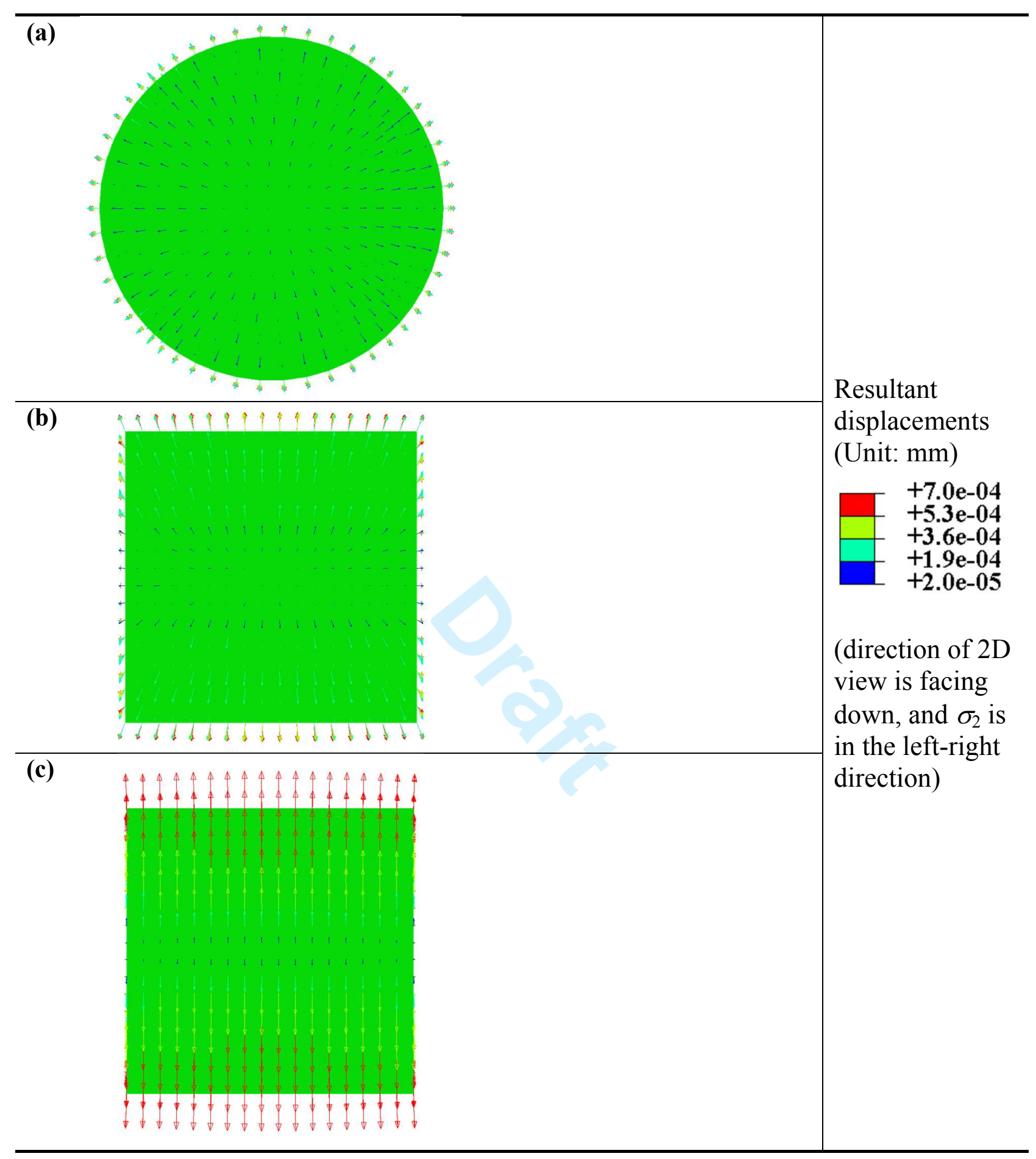

Figure 14. Resultant displacements at peak load on the plane cutting through the midheight of the Westerly granite specimens. 


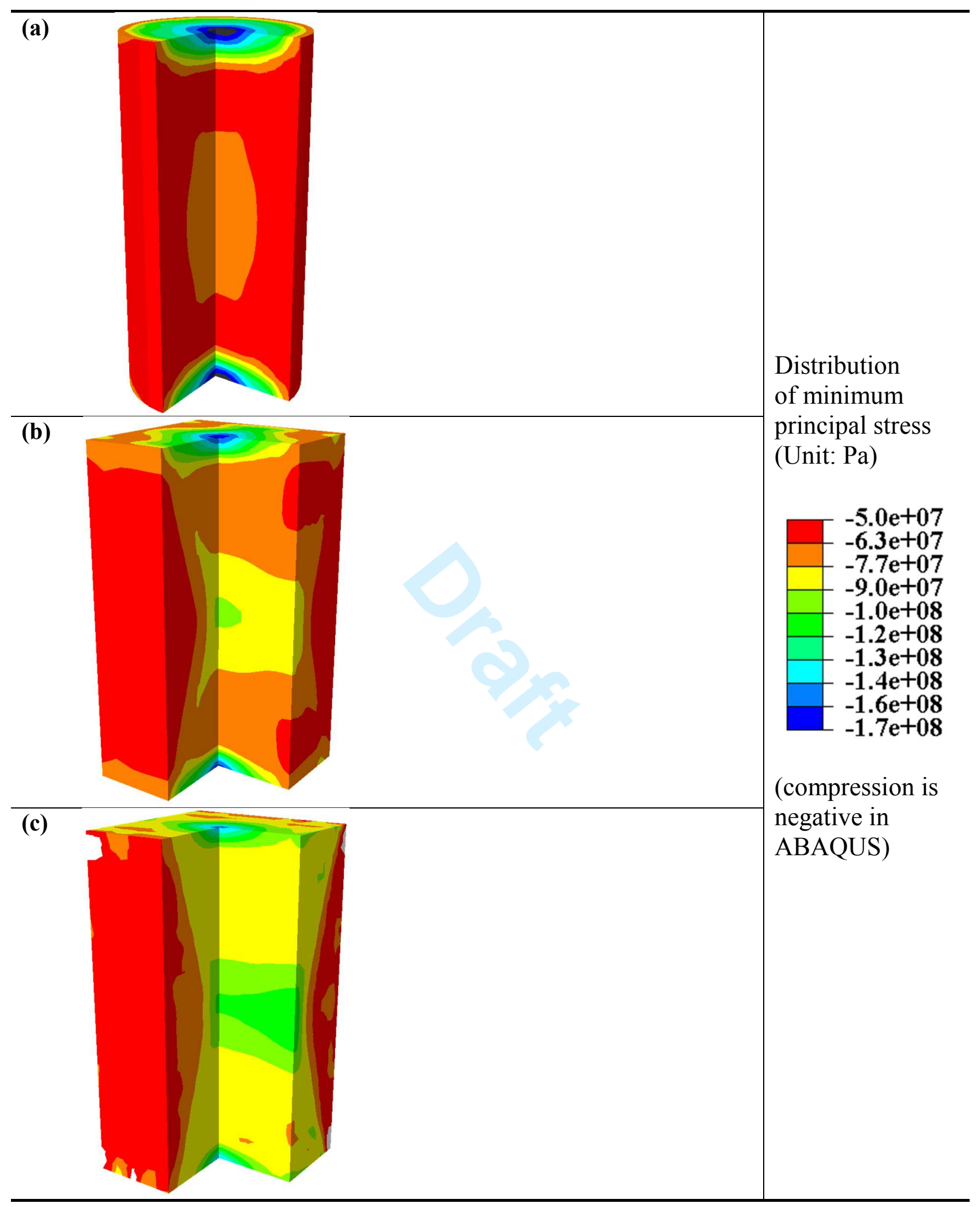

Figure 15. $\sigma_{3}$ contours in the Westerly granite specimens at peak load. 

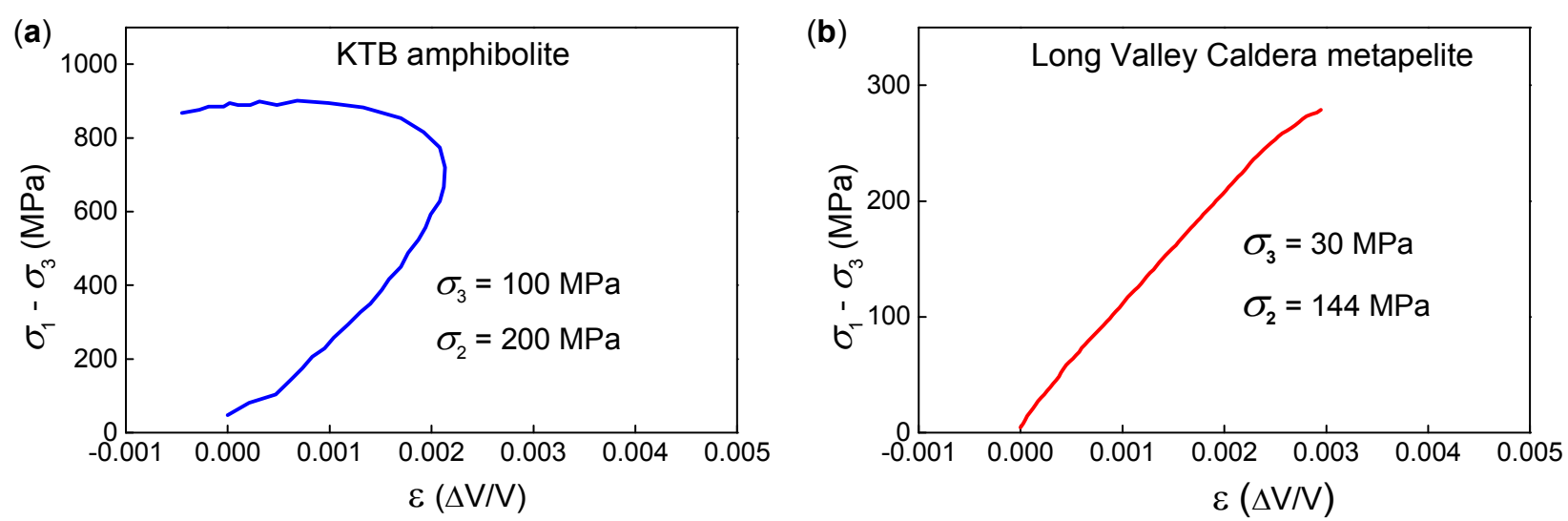

Figure 16. Deviatoric stress-volumetric strain curves for: (a) KTB amphibolite and (b) Long Valley Caldera metapelite in true triaxial compression tests (digitized and modified from Chang and Haimson, 2000 and Chang and Haimson, 2005, respectively).

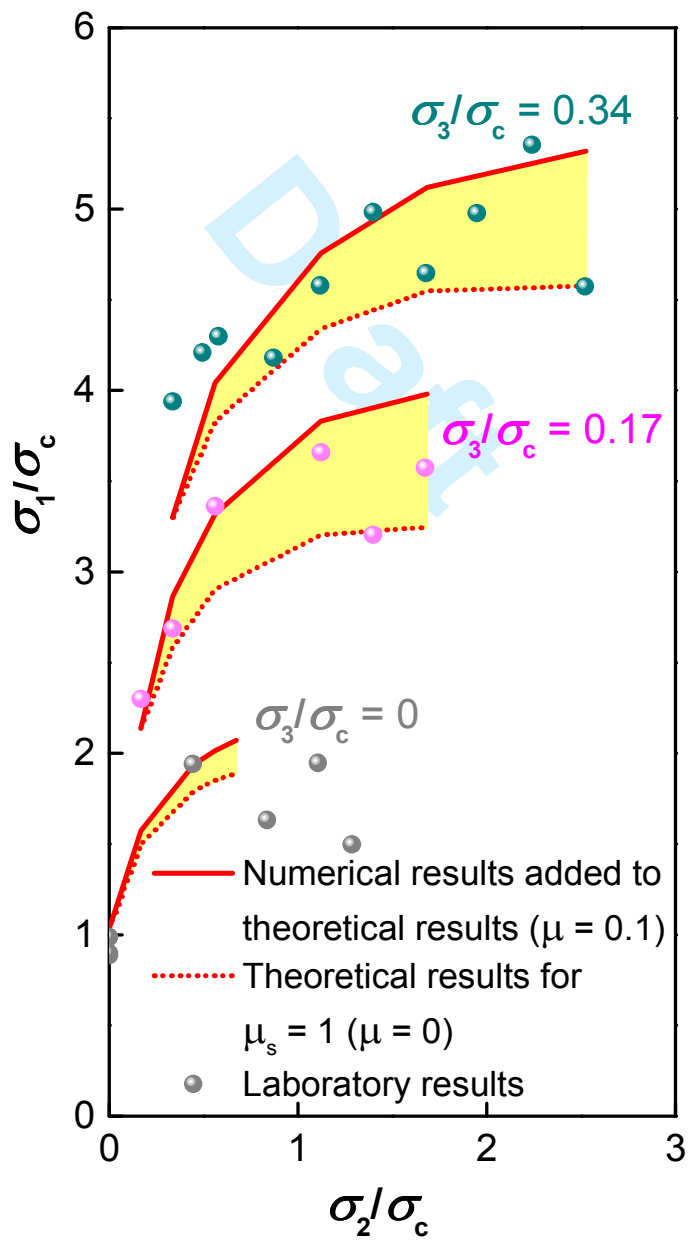

Figure 17. Combination of numerical end effect and theoretical $\sigma_{2}$ effect on rock strength, compared with the experimental data of KTB amphibolite. 


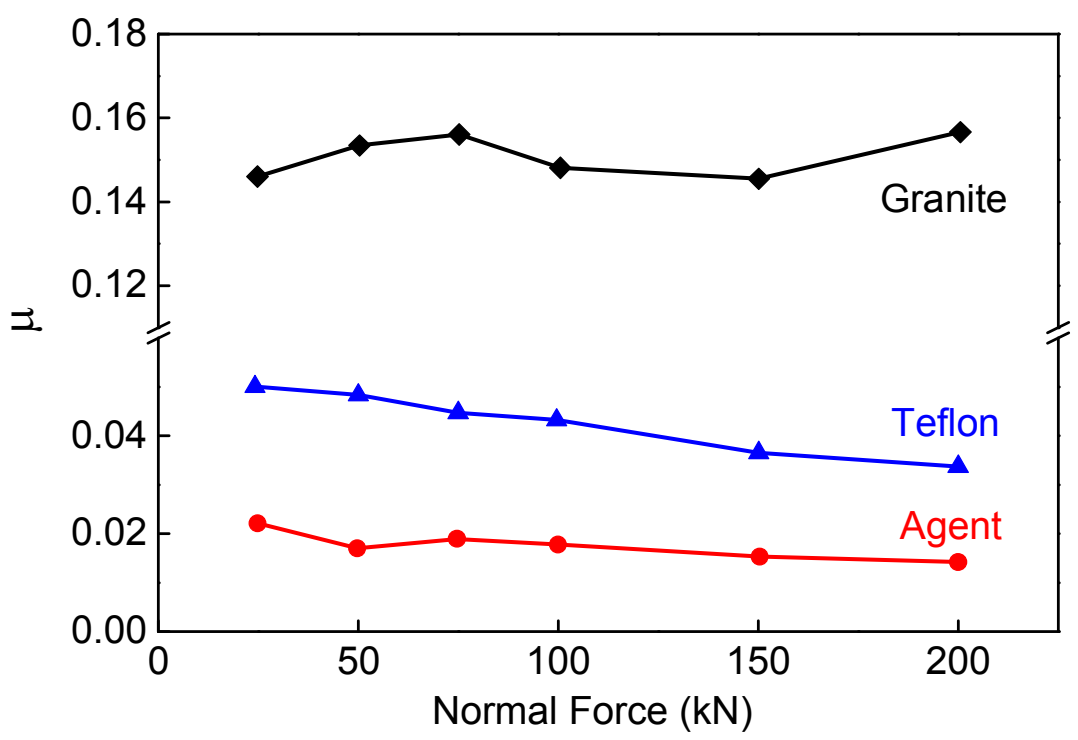

Figure 18. $\mu$ values of rock specimen-steel platen contacts measured by shear tests with different normal forces.

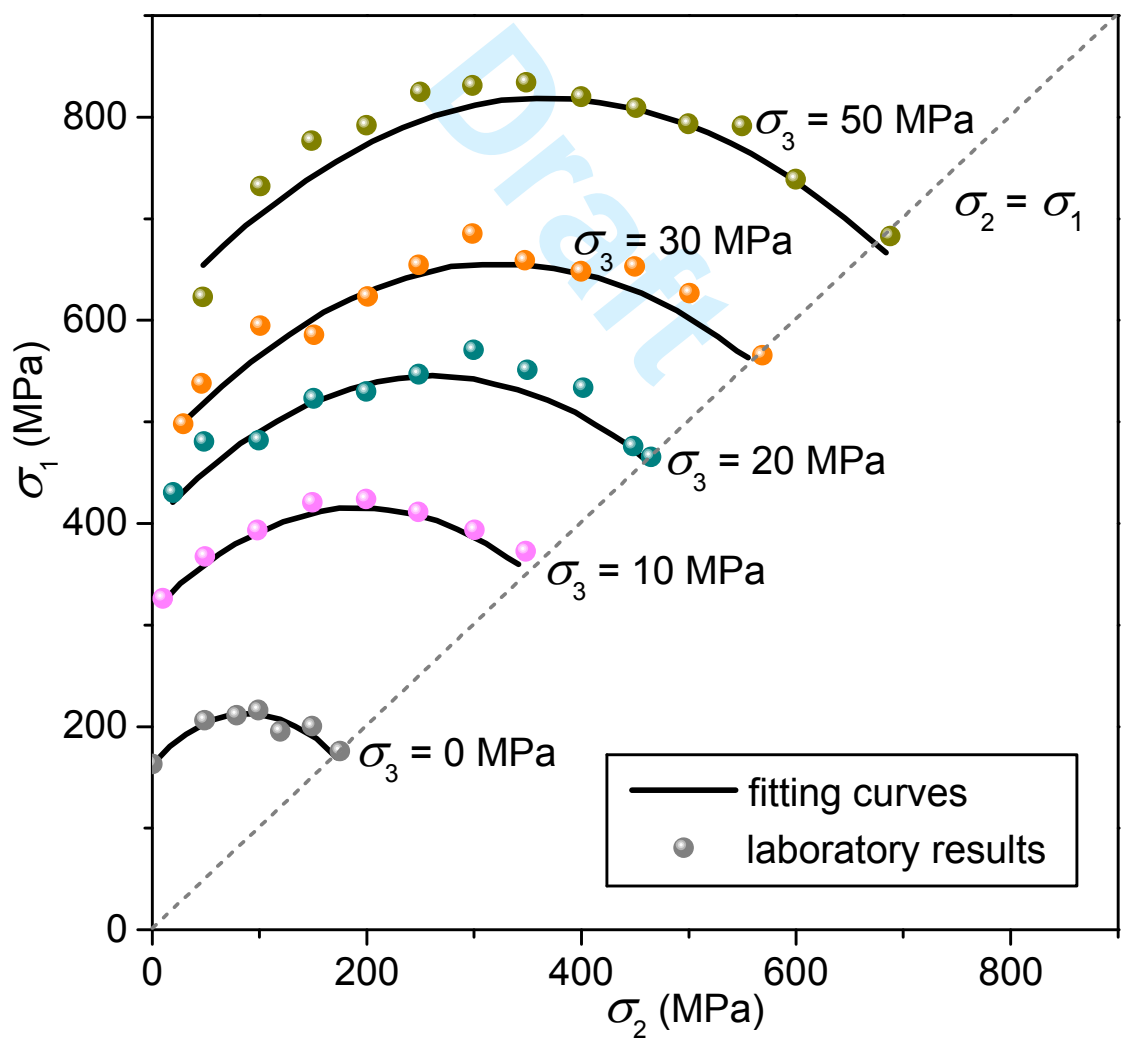

Figure 19. Laboratory true triaxial compression test results showing the $\sigma_{2}$ effect on the strength of Linghai granite. 


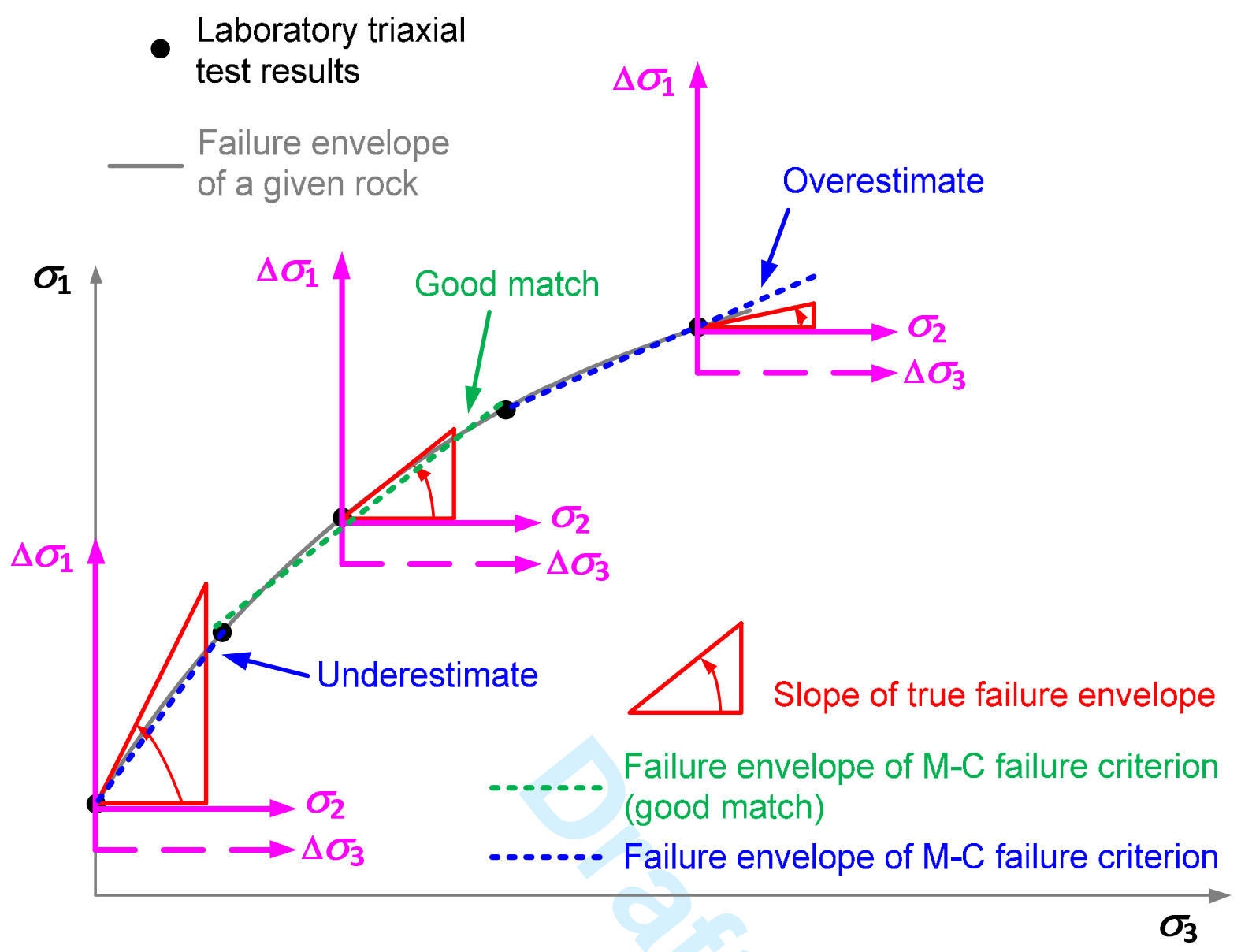

Figure 20. Comparison of end-effect-induced $\sigma_{2}$ effect (refer to pink coordinate system) at different applied $\sigma_{3}$ levels (refer to grey coordinate system). 
- Laboratory results
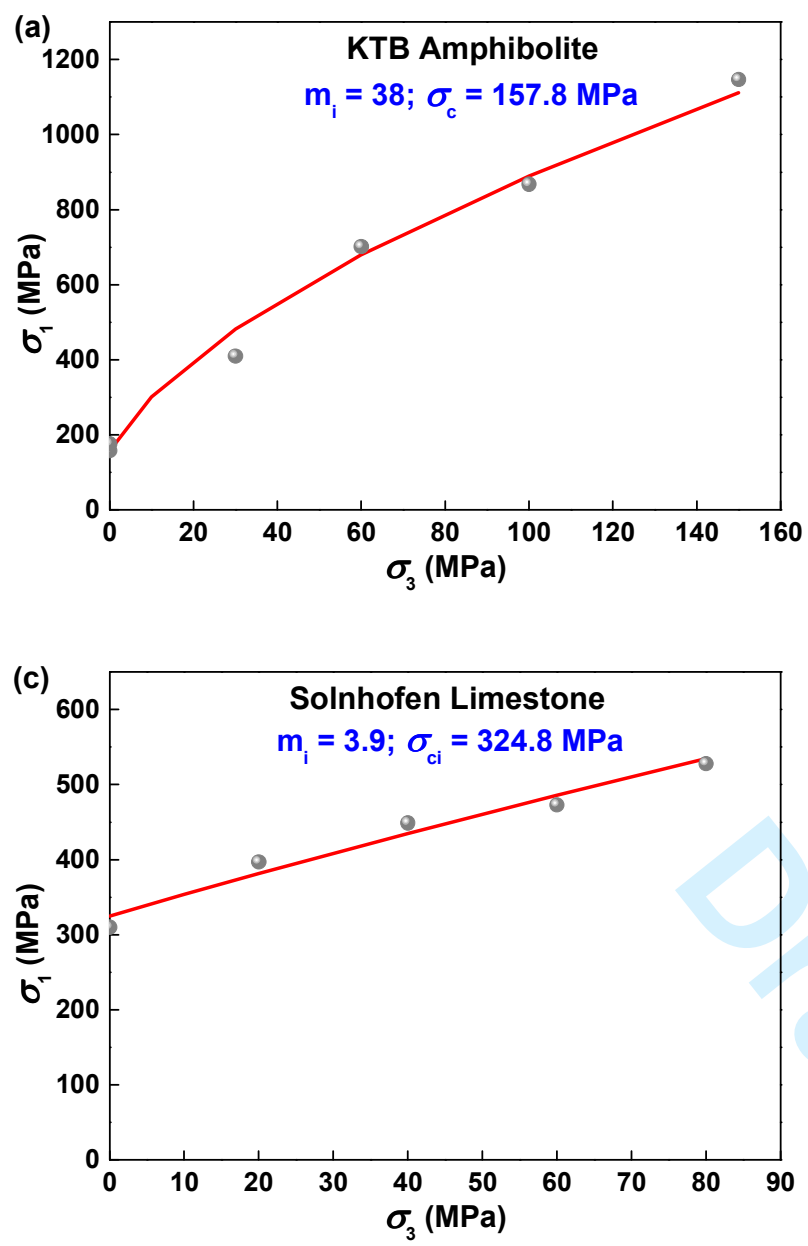
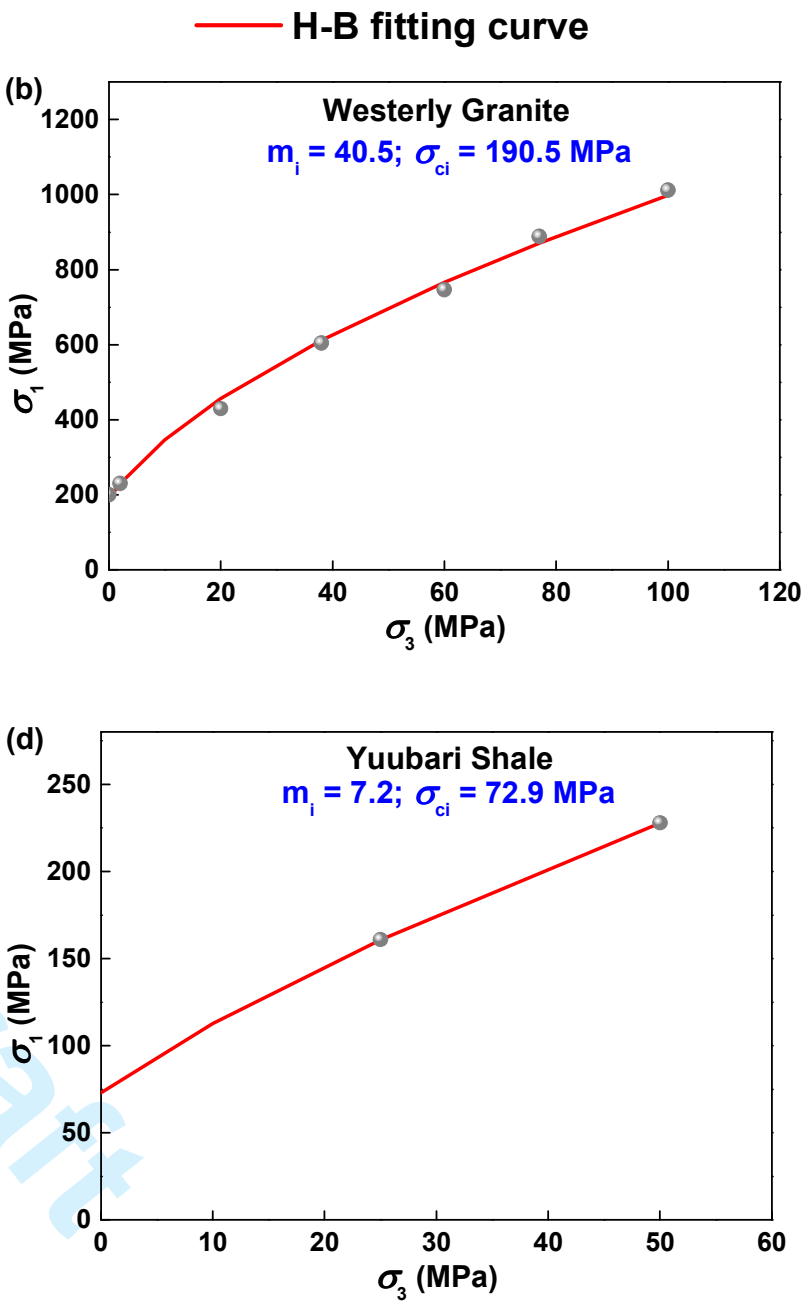

Figure 21. Conventional triaxial compression test results of some rocks and their $H-B$ fitting curves: (a) KTB amphibolite, (b) Westerly granite, (c) Solnhofen limestone, (d) Yuubari shale (Takahashi and Koide, 1989; Chang and Haimson, 2000; Haimson and Chang, 2000; Mogi, 2007). 